\title{
Structure of $\mathrm{Rh} / \mathrm{TiO} 2$ in the normal and the SMSI state as determined by extended X-ray absorption fine structure and high-resolution transmission electron microscopy
}

Citation for published version (APA):

Martens, J. H. A., Prins, R., Zandbergen, H., \& Koningsberger, D. C. (1988). Structure of Rh/TiO2 in the normal and the SMSI state as determined by extended X-ray absorption fine structure and high-resolution transmission electron microscopy. Journal of Physical Chemistry, 92(7), 1903-1916. https://doi.org/10.1021/j100318a041

DOI:

10.1021/j100318a041

Document status and date:

Published: 01/01/1988

Document Version:

Publisher's PDF, also known as Version of Record (includes final page, issue and volume numbers)

\section{Please check the document version of this publication:}

- A submitted manuscript is the version of the article upon submission and before peer-review. There can be important differences between the submitted version and the official published version of record. People interested in the research are advised to contact the author for the final version of the publication, or visit the DOI to the publisher's website.

- The final author version and the galley proof are versions of the publication after peer review.

- The final published version features the final layout of the paper including the volume, issue and page numbers.

Link to publication

\footnotetext{
General rights

- You may freely distribute the URL identifying the publication in the public portal. follow below link for the End User Agreement:

www.tue.nl/taverne

\section{Take down policy}

If you believe that this document breaches copyright please contact us at:

openaccess@tue.nl

providing details and we will investigate your claim.
}

Copyright and moral rights for the publications made accessible in the public portal are retained by the authors and/or other copyright owners and it is a condition of accessing publications that users recognise and abide by the legal requirements associated with these rights.

- Users may download and print one copy of any publication from the public portal for the purpose of private study or research.

- You may not further distribute the material or use it for any profit-making activity or commercial gain

If the publication is distributed under the terms of Article $25 \mathrm{fa}$ of the Dutch Copyright Act, indicated by the "Taverne" license above, please 


\title{
Structure of $\mathrm{Rh} / \mathrm{TiO}_{2}$ in the Normal and the SMSI State As Determined by Extended $X$-ray Absorption Fine Structure and High-Resolution Transmission Electron Microscopy
}

\author{
J. H. A. Martens, R. Prins, H. Zandbergen, ${ }^{\dagger}$ and D. C. Koningsberger* \\ Laboratory of Inorganic Chemistry and Catalysis, Eindhoven University of Technology, 5600 MB Eindhoven,
} The Netherlands (Received: July 1, 1987)

\begin{abstract}
Extended X-ray absorption fine structure (EXAFS) and high-resolution transmission electron microscopy (HRTEM) have been used to study the structure of a $\mathrm{Rh} / \mathrm{TiO}_{2}$ catalyst. After reduction in $\mathrm{H}_{2}$ at $473 \mathrm{~K}$ (when the catalyst is in the normal state) the metal particles contain on the average five rhodium atoms and are situated preferably on edges of the $\mathrm{TiO}_{2}$ crystallites but also on [101] and to a lesser extent on [001] anatase crystal faces. Reduction in $\mathrm{H}_{2}$ at $723 \mathrm{~K}$ leads to the SMSI state. Besides oxygen neighbors from the support, the rhodium metal atoms in the metal-support interface have $\mathrm{Ti}^{n+}$ neighbors at 3.4 and $4.3 \AA$. These distances and their coordination numbers fit well with a model in which the metal particles rest on a $\mathrm{TiO}_{2}$ suboxide. This indicates that the supporting oxide near the metal particle has been reduced to a suboxide of $\mathrm{TiO}_{2}$. In the SMSI state no indication for coverage has been found with either EXAFS or HRTEM. On the contrary, exposing the catalyst in the SMSI state to oxygen at $100 \mathrm{~K}$ resulted in changes in the EXAFS spectrum due to physisorption of oxygen. Consequently, in the SMSI state the particles are either not covered or are incompletely covered with $\mathrm{TiO}_{x}$. Since a $\mathrm{Rh} / \mathrm{Al}_{2} \mathrm{O}_{3}$ catalyst under the same conditions became partly oxidized, it is evident that for the $\mathrm{Rh} / \mathrm{TiO}_{2}$ catalyst oxidation has been suppressed. This is most probably the result of an electronic influence from the reduced supporting oxide. Even after oxygen admission at room temperature, the rhodium particles on the $\mathrm{TiO}_{x}$ support remain in the metallic state. The $\mathrm{TiO}_{x}$ suboxide in the vicinity of the metal particles starts to reoxidize and the metal-support interaction becomes weaker.
\end{abstract}

\section{Introduction}

In heterogeneous metal catalysis the support is used to provide a large surface area to facilitate the preparation of well-dispersed catalysts and to prevent sintering of the small supported metal particles, in order to preserve their state of high dispersion. It is often found that support materials modify the chemical reactions of the metal catalyst. Examples are shape selectivity induced by a zeolitic support and bifunctional catalysis of metal particles dispersed on an acidic support, where the metal component catalyzes the hydrogenation/dehydrogenation reactions and the acidic support facilitates isomerization of olefinic compounds. In addition, the support may have a more direct influence on the chemical properties of supported metal particles, especially after reduction at high $(>650 \mathrm{~K})$ temperature. Thus, it is well-known that, for metals dispersed on certain transition-metal oxides, the capacity to adsorb hydrogen or carbon monoxide drastically diminishes when the catalyst is reduced at high, rather than low temperatures $(<650$ and usual $>450 \mathrm{~K}$ ) even though the particle size remains unchanges. ${ }^{1-3}$ Non-transition-metal oxides like $\mathrm{Al}_{2} \mathrm{O}_{3}$ and $\mathrm{SiO}_{2}$ do not influence the capacity to adsorb gasses; the decrease in adsorption after reduction at high temperature of the metal particles dispersed on these supports can be accounted for by sintering. Another interesting phenomenon is observed in chemical processes. When metal particles are dispersed on transition-metal oxide supports, their properties in chemical reactions such as (de)hydrogenation and Fischer-Tropsch synthesis differ markedly from those supported on traditional oxides, like $\mathrm{Al}_{2} \mathrm{O}_{3}$ and $\mathrm{SiO}_{2}$.

A clear distinction between the two classes of support materials can be based on their reducibility. Oxides like $\mathrm{Al}_{2} \mathrm{O}_{3}$ and $\mathrm{SiO}_{2}$ are hard to reduce, while transition-metal oxides like $\mathrm{TiO}_{2}$ and $\mathrm{Ta}_{2} \mathrm{O}_{5}$ can be reduced to suboxides at moderate temperatures. These suboxides are thought to be responsible for the inability of the metal particles to adsorb gasses after reduction at high temperature. Most of these suboxides are known to have semiconducting properties. In the first reports dealing with this phenomenon, ${ }^{1-6}$ these semiconducting suboxides were thought to have a strong (electronic) influence on the supported metal particles and the phenomenon was labeled SMSI, an acronym for strong metal-support interaction. Thus, SMSI refers to the state of inability of supported metal particles to adsorb hydrogen and carbon monoxide, invoked by a reduction at temperatures where

\footnotetext{
${ }^{\dagger}$ Gorlaeus Laboratory, State University Leiden, Leiden, The Netherlands
}

the support is known to be at least partially reduced

Oxidation at mild temperatures $(>450 \mathrm{~K})$ restores both the original oxide and the original properties (i.e., the properties when reduced at mild temperatures) of the metal particles, demonstrating that suboxide formation and inability to adsorb hydrogen and carbon monoxide are related. ${ }^{1,6-8}$ Hence, the SMSI state can be removed under (slightly) oxidizing conditions at elevated temperatures.

Since the first discovery, many studies have been devoted to SMSI. In addition to the model based on an electronic effect several other explanations for SMSI have been suggested. The most important of them is the coverage model. ${ }^{9-17}$ Reduced transition-metal oxides can wet metal, in contrast to unreduced oxides. Thus, it has been suggested that, after reduction at high temperature, the suboxides cover the metal particles and consequently reduce their capacity to adsorb gasses.

SMSI has so far been studied mostly by using model systems like metal films deposited on oxidized titanium $\left(\mathrm{TiO}_{2}\right)$, or $\mathrm{TiO}_{x}$ deposited on a metal. The techniques frequently used in these studies are "surface sensitive", such as Auger and XPS, and in

(1) Tauster, S. J.; Fung, S. C.; Garten, R. L. J. Am. Chem. Soc. 1978, 100 , 170

(2) Tauster, S. J.; Fung, S. C. J. Catal. 1978, 55, 29

(3) Tauster, S. J.; Fung, S. C.; Baker, R. T. K.; Horsley, J. A. Science (Washington, D.C.) 1981, 211, 1121 .

(4) Horsley, J. A. J. Am. Chem. Soc. 1979, 101, 2870.

(5) Baker, R. T. K.; Prestridge, E. B.; Garten, R. L. J. Catal. 1979, 56 390. (6)

6) Baker, R. T. K.; Prestridge, E. B.; Garten, R. L. J. Catal. 1979, 59, (7) $\mathrm{van}$

298,60

(8) Meriaudeau, P.; Ellestad, O. H.; Dufaux, M.; Naccache, C. J. Catal. $1982,75,243$.

(9) Meriaudeau, P.; Dutel, J. F.; Dufaux, M.; Naccache, C. Stud. Surf. Sci. Catal. 1982, 11 .

(10) Belton, D. N.; Sun, Y.-M.; White, J. M. J. Phys. Chem. 1984, 88, 1690.

(11) Belton, D. N.; Sun, Y.-M.; White, J. M. J. Phys. Chem. 1984, 88, 5172

(12) Simoens, A. J.; Baker, R. T. K.; Dwyer, D. J.; Lund, C. R. F.; Madon,

R. J. J. Catal. 1984, 86, 359.

(13) Chung, Y. M.; Xiong, G.; Kao, C. C. J. Catal. 1984, 85, 237.

(14) Sadeghi, H. R.; Henrich, V. E. J. Catal. 1984, 87, 279.

(15) Sun, Y.-M.; Belton, D. N.; White, J. M. J. Phys. Chem. 1986, 90 , 5178

(16) Ko, G. S.; Gorte, R. J. J. Catal. 1984, 90, 59

(17) Raub, G. B.; Dumesic, J. A. J. Phys. Chem. 1984, 88, 660. 
the majority of cases these studies report coverage. These techniques however are not truly surface sensitive. In XPS even up to five layers of the sample can contribute to the spectrum and the results of sputtering can be questioned because of the destructive character of the technique. Kelley et al., ${ }^{18}$ using EELS and other surface-sensitive techniques, did not report complete coverage. Their results pointed rather to "electron structural changes" in both metal and support.

Recently, evidence for alloy formation under SMSI-like conditions has been reported by Beard and Ross. ${ }^{19}$ In the alloy formation model it is assumed that part of the $\mathrm{TiO}_{2}$ supporting oxide is reduced to metallic $\mathrm{Ti}$ and forms an alloy with the supported metal particles. For each noble metal (M) at least three stable titanium alloys are known: $\mathrm{M}_{3} \mathrm{Ti}, \mathrm{MTi}$, and $\mathrm{MTi}_{3}$. It has been shown that alloying can reduce the hydrogen and carbon monoxide adsorption capacity as well ${ }^{20}$ and alloying may therefore be another plausible explanation for SMSI.

$\mathrm{Up}$ to now, no hard evidence in favor of any of the models to explain SMSI in real catalysts has been presented in literature. The model of covered metal particles, though, has been accepted most widely. In addition, suggestions have been made that coverage alone cannot explain the anomalous properties of the supported metal particles under SMSI conditions, and it has been said that an electronic influence of the covering oxide on neigh boring (bare) metal sites might also play an important role. ${ }^{10-13,16,17}$

EXAFS has proven to be an excellent tool to investigate the local environment around metal atoms in a supported metal catalyst. ${ }^{21,22}$ Since only metal atoms in the metal-support interface will be sensitive to changes in the supporting oxide and because only surface metal atoms will be sensitive to (changes in) coverage, it is evident that highly dispersed catalysts must be used. Furthermore, since the contribution to EXAFS spectra of the low- $Z$ atoms of the support $\left(\mathrm{O}^{2-}\right.$ and $\left.\mathrm{Ti}^{4+}\right)$ will be low, high-quality data are a prerequisite as well. In a preceding study, we presented the results of an EXAFS study of the structure of the rhodium metal particles in a $\mathrm{Rh} / \mathrm{TiO}_{2}$ catalyst. This highly dispersed $2.85 \mathrm{wt} \% \mathrm{Rh} / \mathrm{TiO}_{2}$ catalyst was studied after reduction at low temperature and high temperature, the latter leading to the SMSI state. After reduction at low temperature, the $\mathrm{Rh}-\mathrm{Rh}$ coordination number was 3.2 , proving that the metal particles were very small indeed. The rhodium atoms in the metal-support interface had oxygen neighbors at $2.75 \AA$. These oxygen neighbors originated from the support. From this it was concluded that the metal particles rested on a [001] anatase crystal face. When reduced at higher temperature, in the EXAFS spectrum a $3.4-\AA$ $\mathrm{Rh}-\mathrm{Ti}$ contribution could be detected, indicating that the [001] anatase crystal face was reduced as well. Since the $\mathrm{Rh}^{0}-\mathrm{O}^{2-}$ coordination number hardly changed upon reduction at higher temperature and no other type of oxygen neighbors could be detected, we concluded that with EXAFS no evidence for coverage was found.

In the following, we will present the results of a consecutive EXAFS study of a highly dispersed $4 \mathrm{wt} \% \mathrm{Rh} / \mathrm{TiO}_{2}$ catalyst in the "normal" and the "SMSI" state. Because of the higher metal loading, a better signal-to-noise ratio could be realized. Highresolution transmission electron microscopy (HRTEM) has been used to verify the average metal particle size determined by EXAFS. Since in our earlier EXAFS study we found no evidence for coverage, we have complemented these experiments by investigating the catalyst after reduction at higher temperature ( 723 $\mathrm{K}$ compared to $673 \mathrm{~K}$ in the previous study) and we have studied the influence of oxygen on the metal particles in the normal and the SMSI state. After reduction at $723 \mathrm{~K}$ and evacuation at 623 235

(18) Kelley, M. J.; Short, D. R.; Swartzfager, D. E. J. Catal. 1983, 20

(19) Beard, B. C. Ross, P. N. J. Phys. Chem. 1984, 90, 6811.

(20) Brewer, L In Phase Stability in Metals and Alloys. Rudman, P Stringer, J., Jaffee, R., Eds.; McGraw-Hill: New York, 1967; pp 39-61

(21) Sinfelt, J. H.; Via, G. H.; Lytle, F. W. J. Chem. Phys. 1977, 67, 3831

(22) van't Blik, H. F. J.; van Zon, J. B. A. D. Huizinga, T.; Koningsberger,

D. C.; Prins, R. J. Phys. Chem. 1983, 87, 2264

(23) Koningsberger, D. C.; Martens, J. H. A.; Prins, R.; Short, D. R Sayers, D. E.J. Phys. Chem. 1986, $90,3047$.
$\mathrm{K}$, the $\mathrm{Rh} / \mathrm{TiO}_{2}$ catalyst was exposed to oxygen at liquid nitrogen temperature and at room temperature and after each exposure an EXAFS spectrum was recorded. The same experiments were carried out on a $\mathrm{Rh} / \mathrm{Al}_{2} \mathrm{O}_{3}$ catalyst in order to study oxygen adsorption on "normal" rhodium metal particles.

\section{Experimental Section}

In order to obtain highly dispersed catalysts, a high surface area support is imperative. Since surface areas of commercially available $\mathrm{TiO}_{2}$ are low, in the range of $10-50 \mathrm{~m}^{2} \mathrm{~g}^{-1}$, we prepared our own $\mathrm{TiO}_{2}$ support according to the following procedure. A solution of $8 \mathrm{~mL}$ of $\mathrm{Ti}\left(\mathrm{OC}_{3} \mathrm{H}_{7}\right)_{4}$ in $200 \mathrm{~mL}$ of ethanol was added slowly, dropwise, to $4 \mathrm{~L}$ of a 1:1 well-stirred mixture of ice and distilled water. The precipitated $\mathrm{Ti}(\mathrm{OH})_{4}$ was filtered off, washed with distilled water, and dried for $24 \mathrm{~h}$ at room temperature, 1 $\mathrm{h}$ at $363 \mathrm{~K}$ (heating rate $1 \mathrm{~K} \mathrm{~min}^{-1}$ ), and finally $12 \mathrm{~h}$ at $393 \mathrm{~K}$ (heating rate $1 \mathrm{~K} \mathrm{~min}^{-1}$ ). The sample was powdered and calcined for $3 \mathrm{~h}$ at $923 \mathrm{~K}$ (heating rate $5 \mathrm{~K} \mathrm{~min}^{-1}$ ). The uncalcined sample had a surface area of $700 \mathrm{~m}^{2} \mathrm{~g}^{-1}$. After calcination the surface area had decreased to $130 \mathrm{~m}^{2} \mathrm{~g}^{-1}$ and the pore volume was 0.65 $\mathrm{mL} \mathrm{g}^{-1}$. Calcining for longer than $3 \mathrm{~h}$ at $923 \mathrm{~K}$ did not affect surface area or pore volume.

A 4 wt $\% \mathrm{Rh} / \mathrm{TiO}_{2}$ catalyst was prepared by adding $5 \mathrm{~mL}$ of an aqueous solution of $\mathrm{Rh}\left(\mathrm{NO}_{3}\right)_{3} \cdot 6 \mathrm{H}_{2} \mathrm{O}\left(90 \mathrm{mg} \mathrm{mL}^{-1}\right)$ to $3 \mathrm{~g}$ of $\mathrm{TiO}_{2}$. After $48 \mathrm{~h}$, the $\mathrm{TiO}_{2}$ with adsorbed $\mathrm{Rh}^{3+}$ was filtered off, washed, filtered off, and dried as described above for the $\operatorname{Ti}(\mathrm{OH})_{4}$ precipitate (heating rate $5 \mathrm{~K} \mathrm{~min}^{-1}$ ). The dried catalyst was calcined at $623 \mathrm{~K}$ for $3 \mathrm{~h}$ (heating rate $5 \mathrm{~K} \mathrm{~min}^{-1}$ ). This sample was used as starting material for further experimentation.

The $\mathrm{H} / \mathrm{Rh}$ value as determined by hydrogen chemisorption for the calcined sample after reduction at $525 \mathrm{~K}$ was found to be 1.2 . Recently we published an empirical calibration of hydrogen chemisorption with EXAFS results for several supported rhodium, platinum, and iridium catalysts. ${ }^{24}$ According to this calibration a $\mathrm{H} / \mathrm{Rh}$ value of 1.2 corresponds to a EXAFS $\mathrm{Rh}-\mathrm{Rh}$ coordination number in the range of 7-8. For half-spherical particles, this coordination number corresponds to particles containing roughly 40-60 atoms and thus to rather large metal particles. However, as will be discussed, our EXAFS results and Highresolution transmission electron microscopy prove that the metal particles are very small with five or six metal atoms per particle and a particle size of about $7 \AA$. Two explanations for this contradiction are possible. In the first place, the rhodium metal particles in the present sample are much smaller than the (rhodium) metal particles in the most highly dispersed catalyst in ref 24. Their chemistry, therefore, may deviate from the behavior of the larger metal particles in hydrogen atmosphere as described in ref 24. Because of their size, the small rhodium metal particles approach the quantum size limit and consequently may not be able to adsorb as much hydrogen per surface metal atom as a larger (fully metallic) particle. Another plausible explanation is that during reduction at $525 \mathrm{~K}$ the formation of $\mathrm{TiO}_{x}$ suboxides has already started and that the influence of SMSI is reflected in a low adsorption capacity of these very small rhodium particles. After reduction at $723 \mathrm{~K}$, the $\mathrm{H} / \mathrm{M}$ value decreased to 0.2 , indicating that the catalyst is in the SMSI state.

In temperature-programmed reduction, a sharp peak at 330 $\mathrm{K}$ was observed for the calcined catalyst. After oxidation at 773 $\mathrm{K}$, the temperature-programmed reduction profile contains one single and sharp peak at $350 \mathrm{~K}$. According to Vis et al., ${ }^{25}$ a TPR reduction peak at $330-350 \mathrm{~K}$ corresponds to highly dispersed metal particles.

EXAFS spectra were recorded at the synchrotron radiation source (SRS) in Daresbury, United Kingdom. The storage ring was operated at 1.8 or $2.0 \mathrm{GeV}$, and the ring current was in the range of 100-300 $\mathrm{mA}$. The samples were pressed into thin self-supporting wafers. The thickness of the wafers was chosen

(24) Kip, B. J.; Duivenvoorden, F. B. M.; Koningsberger, D. C.; Prins, R. J. Catal. 1984, 105, 26

(25) Vis, J. C.; van't Blik, H. F. J.; Huizinga, T.; van Grondelle, J.; Prins, R. J. Mol. Catal. 1984, 25, 367. 
to give an absorbance $(\mu x)$ of 2.5 , assuring an optimum signalto-noise ratio. The pressed samples were mounted in an in situ EXAFS cell, enabling in situ treatments and measurements in different gas atmospheres. The EXAFS spectra of the rhodium $\mathrm{K}$ edge were recorded with the sample at approximately $100 \mathrm{~K}$. EXAFS spectra of the reference compounds were recorded at room temperature.

The experiments on the catalyst were carried out in two series. In all cases the heating rate was $5 \mathrm{~K} \mathrm{~min}^{-1}$. After each pretreatment an EXAFS spectrum was recorded. The samples were cooled by using liquid nitrogen; the temperature of the samples was approximately $100 \mathrm{~K}$. In the first series, the catalyst was reduced at $473 \mathrm{~K}$ for $0.5 \mathrm{~h}$ and subsequently at $723 \mathrm{~K}$ for $1 \mathrm{~h}$. In the second series, a fresh (calcined) sample was reduced at 723 $\mathrm{K}$ for $1 \mathrm{~h}$ and subsequently evacuated at $623 \mathrm{~K}$ for $2 \mathrm{~h}$. After the EXAFS spectrum was recorded, a small amount of $\mathrm{O}_{2}$ was admitted to the evacuated sample at $100 \mathrm{~K}$. After an EXAFS spectrum was recorded, the sample was allowed to warm up to room temperature and after $10 \mathrm{~min}$ at room temperature an EXAFS spectrum was recorded at liquid nitrogen temperature. The same experiments have been carried out with a $\mathrm{Rh} / \mathrm{Al}_{2} \mathrm{O}_{3}$ catalyst after reduction at $623 \mathrm{~K}$.

Phase shifts and backscattering amplitudes from reference compounds were used to calculate EXAFS spectra and to correct in the Fourier transformations for the $k$ dependence in both phase shifts and backscattering functions. Rhodium foil was used as a reference for $\mathrm{Rh}-\mathrm{Rh}$ contributions, $\mathrm{Rh}_{2} \mathrm{O}_{3}$ for $\mathrm{Rh}-\mathrm{O}$, and $\mathrm{RhT} i$ alloy for $\mathrm{Rh}-\mathrm{Ti}$ contributions in the EXAFS spectra. The RhTi alloy was prepared by arc melting equimolar amounts of rhodium and titanium. The structure and homogeneity were checked by $\mathrm{X}$-ray diffraction and microprobe analysis. After careful powdering and sieving, $43 \mathrm{mg}$ of the alloy was mixed and crushed with $32 \mathrm{mg}$ of $\mathrm{Al}_{2} \mathrm{O}_{3}$ and pressed into a self-supporting wafer with absorbance $\mu x=2.5$. For $\mathrm{Rh}_{2} \mathrm{O}_{3}$, a supporting wafer with an absorbance of 2.5 was prepared in the same way ( $70 \mathrm{mg}$ of $\mathrm{Rh}_{2} \mathrm{O}_{3}$ and $30 \mathrm{mg}$ of $\mathrm{Al}_{2} \mathrm{O}_{3}$ ). A rhodium foil was chosen with a thickness of $20 \mu \mathrm{m}$ thick, $\mu x=1.4$.

Before the HRTEM experiments, the 4 wt $\% \mathrm{Rh} / \mathrm{TiO}_{2}$ catalyst was reduced at $773 \mathrm{~K}$ in a $4 \% \mathrm{H}_{2}$ in Ar mixture (heating rate $5 \mathrm{~K} \mathrm{~min}^{-1}$ ). After the reduction treatment the catalyst was carefully passivated at room temperature in a $4 \% \mathrm{O}_{2}$ in $\mathrm{He}$ mixture. In order to study the passivated sample in the electron microscope, the catalyst was suspended in methanol. A droplet of this suspension was put on a carbon-coated Formvar holey copper grid. For the HRTEM recordings, an objective aperture of $7 \mathrm{~nm}^{-1}$ was used. The photographs were taken with a magnification of $5 \times 10^{5}$ and an exposure time of $1 \mathrm{~s}$.

An electron microscope image is formed from two contributions, the absorption contrast and the phase contrast. Absorption contrast originates primarily from an intensity deficiency caused by the exclusion of a number of electrons with scattering angles larger than the aperture used. Secondly, inelastically scattered electrons will have wavelengths different from the incident and elastically scattered electrons and will contribute only nonconstructively to the image. Phase contrast arises from constructive interference of diffracted and undiffracted electrons within the aperture used.

When low scattering and thin supports are used, metal particles can be detected best at focus values very close to zero. Since at this focus phase contrast is almost zero, absorption contrast, due to the higher electron scattering amplitude of the metal particles, is most pronounced. However, near zero focus, the resolution of the absorption contrast is approximately twice the point resolution of the microscope and the particle size determinations will have about the same uncertainty. Since the point resolution of the microscope used is approximately $2.4 \AA$, the uncertainty in the particle sizes is about $5 \AA$, provided no image calculations are carried out. The best resolution is obtained near Scherzer focus, where, for thin specimen, phase contrast dominates the absorption contrast. Here, the uncertainty is about the point resolution of the microscope. Compared to zero focus, where absorption contrast dominates, the visibility of the metal particles is worse
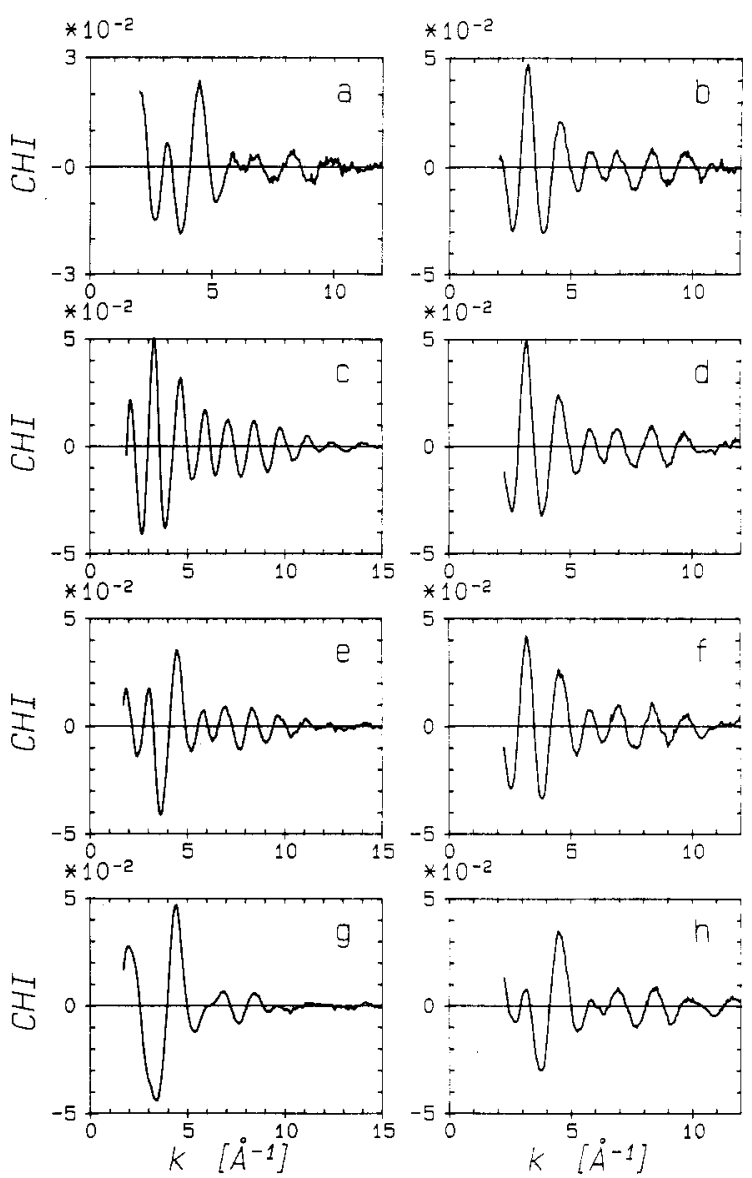

Figure 1. Raw EXAFS data of (a) $\mathrm{Rh} / \mathrm{TiO}_{2}$ after reduction at $473 \mathrm{~K}$ (b) $\mathrm{Rh} / \mathrm{TiO}_{2}$ after reduction at $723 \mathrm{~K}$; (c) $\mathrm{Rh} / \mathrm{Al}_{2} \mathrm{O}_{3}$ after reduction and evacuation at $623 \mathrm{~K}$; (d) $\mathrm{Rh} / \mathrm{TiO}_{2}$ after reduction at $723 \mathrm{~K}$ and evacuation at $623 \mathrm{~K}$; (e) $\mathrm{Rh} / \mathrm{Al}_{2} \mathrm{O}_{3}$ after oxygen exposure at $100 \mathrm{~K}$; (f) $\mathrm{Rh} / \mathrm{TiO}_{2}$ after oxygen admission at $100 \mathrm{~K} ;(\mathrm{g}) \mathrm{Rh} / \mathrm{Al}_{2} \mathrm{O}_{3}$ after oxygen admission at $300 \mathrm{~K} ;(\mathrm{h}) \mathrm{Rh} / \mathrm{TiO}_{2}$ after oxygen exposure at $300 \mathrm{~K}$.

at Scherzer focus. We have taken a number of photographs at different focus. Such a through-focus series can help to identify the presence of metal particles (at zero focus) and to determine their size (at Scherzer focus). Therefore, the uncertainty in the metal particle size determined in this way is about the point resolution of the microscope, which is $2.4 \AA$.

In case of very small metal particles, it is difficult to distinguish them from artifacts. There is also the possibility that very small particles are overlooked. Partial in situ sintering of the metal particles with a very intense electron beam can help in this respect. By comparing the total volumes of the metal particles before and after sintering, an estimation can be obtained of the metal particle size before sintering. The in situ sintering experiment has been performed by taking out the condensor aperture and focusing the electron beam on the agglomerate of $\mathrm{TiO}_{2}$ crystallites and rhodium particles. The degree of sintering can be regulated by the focus of the condensor lens.

\section{Results}

1. Analysis of the EXAFS Spectra. The EXAFS functions $(\chi(k))$ were obtained from the $X$-ray absorption spectra by subtracting a Victoreen curve, followed by a cubic spline background removal. ${ }^{26}$ Normalization was performed by division to the height of the edge. In Figure 1, the raw EXAFS functions of the $\mathrm{Rh} / \mathrm{TiO}_{2}$ catalyst after reduction at 473 and at $723 \mathrm{~K}$ and the raw EXAFS functions of the $\mathrm{Rh} / \mathrm{Al}_{2} \mathrm{O}_{3}$ and $\mathrm{Rh} / \mathrm{TiO}_{2}$ catalysts after evacuation at $623 \mathrm{~K}$ and after $\mathrm{O}_{2}$ admission at 100 and 300 $\mathrm{K}$ are shown.

The spectra of the reference compounds, used to obtain phase shifts and backscattering functions, were processed in the same

(26) Cook, J. W.; Sayers, D. E. J. Appl. Phys. 1981, 52, 5024. 
TABLE I: Crystallographic Data and Fourier Transform Ranges for the Reference Compounds

\begin{tabular}{lllrrrr}
\hline & & & & \multicolumn{3}{c}{ Fourier transformation } \\
\cline { 5 - 7 } compd & $\mathrm{NN}^{a}$ & \multicolumn{1}{c}{$R^{b}$} & $N^{c}$ & $n^{d}$ & $k$ range & $r$ range \\
\hline $\mathrm{Rh}$ foil & $\mathrm{Rh}$ & 2.687 & 12 & 3 & $2.16-24.0$ & $1.42-3.00$ \\
$\mathrm{Rh}_{2} \mathrm{O}_{3}$ & 0 & 2.05 & 6 & 1 & $2.35-20.0$ & $0.00-2.10$ \\
$\mathrm{RhTi}$ & $\mathrm{Rh}$ & 2.949 & 4 & 3 & $2.83-16.6$ & $e$ \\
& $\mathrm{Ti}$ & 2.676 & 8 & 1 & $3.00-15.0$ & $1.06-2.59$
\end{tabular}

${ }^{a}$ Nearest neighbor. ${ }^{b}$ Coordination distance $(\AA)$. ${ }^{c}$ Coordination number. "Weighting factor in Fourier transformation. ${ }^{e}$ On these data, no direct inverse transformation has been applied. Crystallographic data derived from ref 27.

way as the catalyst samples. To obtain phase shifts and backscattering amplitudes, the EXAFS spectra of the reference compounds were Fourier transformed over the largest possible range in $k$ space. To avoid cutoff effects, $k_{\min }$ and $k_{\max }$ were chosen in nodes of the EXAFS function. Table I presents the Fourier transform ranges and the crystallographic data for the reference compounds. ${ }^{27}$ In the Fourier transforms of the EXAFS functions of the rhodium foil and $\mathrm{Rh}_{2} \mathrm{O}_{3}$, the $\mathrm{Rh}-\mathrm{Rh}$ and $\mathrm{Rh}-\mathrm{O}$ peaks are clearly separated from higher coordination shells. An inverse transformation over a limited range in $r$ space gave the EXAFS spectra for the single-shell $\mathrm{Rh}-\mathrm{Rh}$ and $\mathrm{Rh}^{3+}-\mathrm{O}^{2-}$ absorberscatterer pairs. Since the Fourier transforms have not been corrected for the $k$ dependence in phase shift and backscattering amplitude, the transforms contain side lobes. These side lobes were included in the inverse transformation range. The required phase and backscattering amplitude have been derived from these spectra.

For the RhTi alloy this procedure was more complex. In the Fourier transform, two contributions are present. The first contribution is from eight titanium neighbors at $2.676 \AA$ and the second from four rhodium neighbors at $2.949 \AA .{ }^{27}$ Since these contributions overlap, they could not be separated by an inverse Fourier transform over a window in $r$ space. A Rh-Rh contribution was calculated by using the phase shift and backscattering amplitude obtained from the rhodium foil. The best agreement in $r$ space in the region of the main $\mathrm{Rh}$-Rh peak in the $k^{3}$-weighted Fourier transform of the measured and calculated EXAFS function was obtained with the following $\mathrm{Rh}-\mathrm{Rh}$ parameters $N$ $=4.0, R=2.95, \Delta \sigma^{2}=0.0042$, and $E_{0}=-1$. ( $N$ is the coordination number, $R$ the coordination distance, $\Delta \sigma^{2}$ the DebyeWaller factor, a measure for the disorder, and $E_{0}$ is a correction on the edge position; see ref 28 for more details.) This calculated $\mathrm{Rh}-\mathrm{Rh}$ EXAFS was subtracted from the experimental data and the difference spectrum was used to obtain the Rh-Ti phase shift and backscattering amplitude. The Fourier transform of the difference spectrum showed one single peak at $2.16 \AA$. The Fourier transform has not been corrected for the $k$ dependence in phase shift and backscattering amplitude. Because of the phase shift, the main peak in the Fourier transform has shifted from the real coordination distance. Inverse transformation over the $r$ range $1.06-2.59$ resulted in the $\mathrm{Rh}-\mathrm{Ti}$ EXAFS function, from which the $\mathrm{Rh}-\mathrm{Ti}$ phase shift and backscattering amplitude could be obtained.

The spectra of the different catalyst samples as presented in Figure 1 may contain several contributions. Because of the higher backscattering amplitude of the high- $Z$ elements, the contribution from rhodium neighbors will be dominant. Other contributions are to be expected from oxygen and possibly from titanium neighbors. The information of the low- $Z$ elements such as oxygen and titanium is limited in $k$ space to about $k=7$ or $8 \AA^{-1}$. For high- $Z$ elements such as rhodium, the information extends, depending on coordination number, up to $k=11$ or $13 \AA^{-1}$ and for high coordination numbers even up to $k=15 \AA^{-1}$. A $k^{3}$-weighted Fourier transform emphasizes the high $k$ part of the EXAFS

(27) Crystal structures: Rh metal, Wyckhof, R. W. G. Crystal Structures; Wiley: New York, 1963; Vol. I, p 10. $\mathrm{Rh}_{2} \mathrm{O}_{3}$, Structure Reports 1974, $40 \mathrm{a}$, 301. RhTi, Structure Reports 1964, 29, 13. spectrum, therefore strongly enhances the high- $Z$ element information relative to the low- $Z$ scatterer information, and has thus been used to separate high- and low- $Z$ scatterer contributions.

For a detailed description of the data analysis procedure, we refer to ref 28-30. Briefly, the analysis consisted of the following steps. An $\mathrm{Rh}-\mathrm{Rh}$ EXAFS function was calculated. The parameters $N, R, \Delta \sigma^{2}$, and $E_{0}$ were chosen to give the best agreement in $r$ space with the main peaks in the $k^{3}$-weighted Fourier transform of the calculated and the measured EXAFS function. This calculated $\mathrm{Rh}-\mathrm{Rh}$ EXAFS spectrum was subtracted from the measured spectrum. In most cases, the resulting difference spectrum contained up to 3 or 4 different contributions. Since it was impossible to further separate these contributions, a 2-, 3-, and 4-shell EXAFS spectrum was calculated and optimized to model the difference spectrum in $k$ space as well as the $k^{1}$-weighted Fourier transform in $r$ space (the Fourier transform was corrected for $\mathrm{Rh}-\mathrm{O}$ phase shift obtained from $\mathrm{Rh}_{2} \mathrm{O}_{3}$ ). In order to calculate $\mathrm{Rh}-\mathrm{O}$ and $\mathrm{Rh}-\mathrm{Ti}$ EXAFS spectra, phase shifts and backscattering amplitudes obtained from $\mathrm{Rh}_{2} \mathrm{O}_{3}$ and $\mathrm{RhTi}$ were used. For each contribution, a separate spectrum was calculated. These calculated spectra were added to give the resulting 2-, 3-, or 4-shell Rh-O, Ti EXAFS spectrum.

The resulting calculated Rh-O, Ti EXAFS function was subtracted from the original spectrum, in order to start an optimization cycle. Since this new difference spectrum contained mostly $\mathrm{Rh}-\mathrm{Rh}$ information, both the $k^{1}$ - and $k^{3}$-weighted Fourier transforms and the data in $k$ space could be used to calculate the best-fitting $\mathrm{Rh}-\mathrm{Rh}$ EXAFS. This improved $\mathrm{Rh}-\mathrm{Rh}$ EXAFS spectrum was subtracted from the original data and the resulting difference spectrum was analyzed to further optimize the $\mathrm{R} h-\mathrm{O}$ and (if present) $\mathrm{Rh}-\mathrm{Ti}$ parameters. In this way a cyclic optimization process was started. The procedure of subtracting a calculated spectrum to separate the information of the low- $Z$ scatterers from the high- $Z$ scatterer was followed until the parameters $N, R, \Delta \sigma^{2}$, and $E_{0}$ for each contribution became constant. Figure 2 shows the $k^{3}$-weighted $\mathrm{Rh}-\mathrm{Rh}$ corrected Fourier transform of the original data and the calculated Rh-Rh EXAFS for all samples are shown. The observed differences are due to low- $Z$ scatterer contributions present in the original data. Figure 3 shows the $k^{1}$-weighted Rh-O corrected Fourier transform of the final difference spectrum (original data minus calculated $\mathrm{Rh}-\mathrm{Rh}$ EXAFS, which contains oxygen and, if present, titanium contributions) and the calculated $\mathrm{Rh}-\mathrm{O}$, Ti EXAFS functions for all samples. Finally, Figure 4 shows the $k^{1}$-weighted $\mathrm{Rh}-\mathrm{Rh}$ corrected Fourier transform of the original EXAFS function and the EXAFS function obtained by adding the calculated $\mathrm{Rh}-\mathrm{Rh}$ and $\mathrm{Rh}-\mathrm{O}$, Ti EXAFS functions. In a $k^{1}$-weighted Fourier transform the low- $Z$ scatterer is much more pronounced compared to a $k^{3}$-weighted Fourier transform (as in Figure 2). From Figures 3 and 4 it is evident that the calculated spectra reproduce the measured spectra extremely well, which emphasizes the reliability of the results.

The structural parameters obtained in this way are presented in Table II. The contributions of the $\mathrm{Rh}-\mathrm{O}$ and $\mathrm{Rh}-\mathrm{Ti}$ absorber-scatterer pairs in the difference spectra are sometimes small and could be due to artifacts induced by an incorrectly calculated $\mathrm{Rh}-\mathrm{Rh}$ EXAFS. In order to ensure that these contributions are indeed real, and to ensure that the set of parameters we obtained is indeed the solution that led to the best fit with the experimental data, for all $\mathrm{Rh} / \mathrm{TiO}_{2}$ catalyst samples $\mathrm{Rh}-\mathrm{Rh}$ EXAFS spectra were calculated for which $N$ and $\Delta \sigma^{2}$, or $R$ and $E_{0}$, were varied over a large range. $\Delta \sigma^{2}$ was varied concurrently with $N$ so as to give a constant magnitude in the $k^{3}$-weighted Fourier transform, while $E_{0}$ was varied concurrently with $R$ in order to prevent the main peak in the Fourier transform of the calculated EXAFS from shifting with respect to the main peak in the Fourier transform

(28) van Zon, J. B. A. D.; Koningsberger, D. C.; van't Blik, H. F. J.; Sayers, D. E. J. Chem. Phys. 1985, 12, 5742

(29) Duivenvoorden, F. B. M.; Koningsberger, D. C.; Uh, Y. S.; Gates, B. C. J. Am. Chem. Soc. 1986, 108,6254 .

(30) van't Blik, H. F. J.; van Zon, J. B. A. D.; Huizinga, T.; Vis, J. C.; Koningsberger, D. C.; Prins, R. J. Am. Chem. Soc. 1985, 107, 3139. 

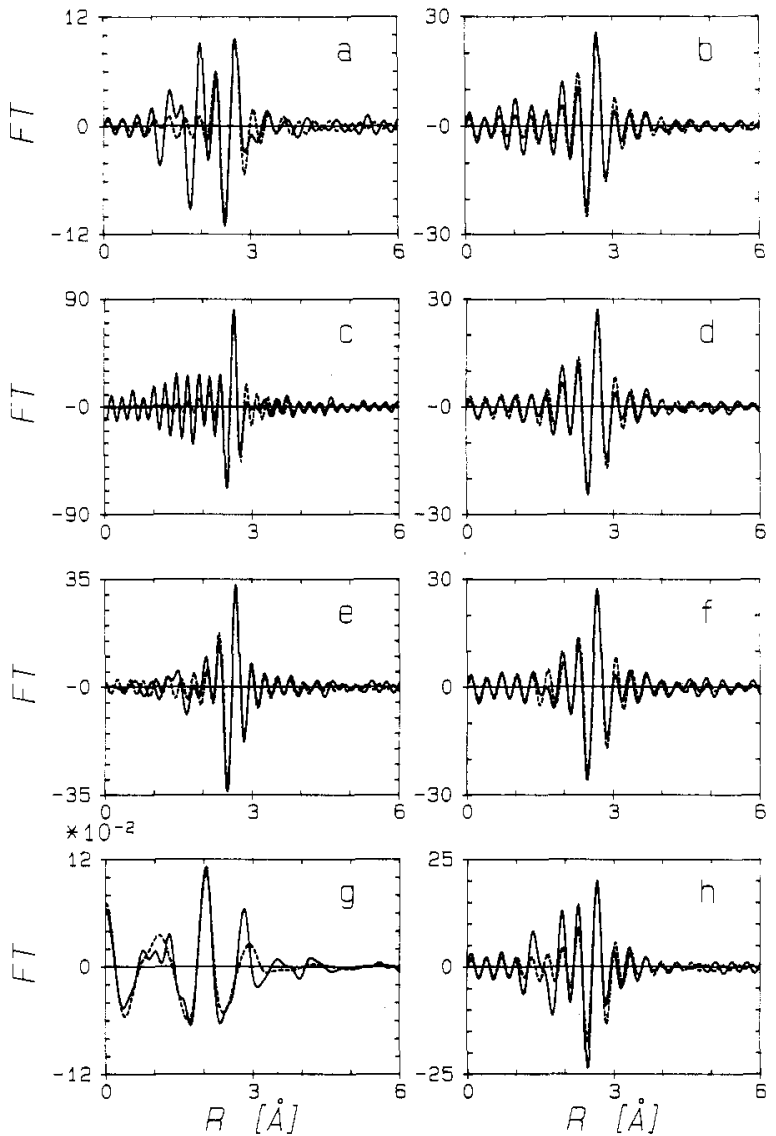

Figure 2. Imaginary parts of the Fourier transforms of the original EXAFS spectra (solid lines) and calculated $\mathrm{Rh}-\mathrm{Rh}$ EXAFS spectra (dashed lines). The Fourier transforms are $k^{3}$-weighted and corrected for the $\mathrm{Rh}-\mathrm{Rh}$ phase shift and backscattering amplitude. The Fourier transform ranges in $k$ space are indicated in parentheses. (a) $\mathrm{Rh} / \mathrm{TiO}_{2}$ after reduction at $473 \mathrm{~K}(3.33-10.24)$; (b) $\mathrm{Rh} / \mathrm{TiO}_{2}$ after reduction at $723 \mathrm{~K}(2.82-10.13)$; (c) $\mathrm{Rh} / \mathrm{Al}_{2} \mathrm{O}_{3}$ after reduction and evacuation at 623 $\mathrm{K}(2.97-14.58)$; (d) $\mathrm{Rh} / \mathrm{TiO}_{2}$ after reduction at $723 \mathrm{~K}$ and evacuation at $623 \mathrm{~K}(2.85-10.06) ;(\mathrm{e}) \mathrm{Rh} / \mathrm{Al}_{2} \mathrm{O}_{3}$ after oxygen exposure at $100 \mathrm{~K}$ (3.26-12.03); (f) $\mathrm{Rh} / \mathrm{TiO}$ after oxygen admission at $100 \mathrm{~K}(2.84$ $10.06) ;(\mathrm{g}) \mathrm{Rh} / \mathrm{Al}_{2} \mathrm{O}_{3}$ after oxygen admission at $300 \mathrm{~K}(2.55-12.45) ;$ In this case, the dashed line represents the dominant $\mathrm{Rh}^{3+}-\mathrm{O}^{2-}$ contribution, the Fourier transform is $k^{1}$-weighted and corrected for $\mathrm{Rh}-\mathrm{O}$ phase shift; (h) $\mathrm{Rh} / \mathrm{TiO}_{2}$ after oxygen exposure at $300 \mathrm{~K}(3.22-10.18)$.

of the original data. In all cases, the difference spectra contained the same features and the same contributions; only the magnitude of the contributions varied slightly with varying $R h-R h$ parameters. In all cases, the data analysis procedure as described above led to the parameters as presented in Table II. The experimental errors have been estimated by slightly varying the parameters in Table II. Small deviations from the "best fit" in the Fourier transform were not allowed. In this way, a good approximation for the experimental errors could be established. The overall errors which are presented in Table II are the sum of this experimental error and an estimation for the systematic error. The systematic error is induced by the procedure of analyzing the data and incorporates errors induced by phase and magnitude transferability, electron main free path, etc.

2. Characterization with HRTEM. The metal particles were observed to have a very uniform and narrow size distribution. In Figure 5, a micrograph near Scherzer focus, the metal particles size was determined to be between 7 and $8 \AA$, the uncertainty being about 2-3 $\AA$, in very good agreement with the results from $\mathrm{EX}$ AFS, based on the Rh-Rh coordination number of 3.2-3.4 (see Discussion). It can be seen that the metal particles seem to favor positions at the edges of the surface planes and not on flat surfaces. The number of metal particles observed on the micrograph is roughly in agreement with the estimated occupation based on the size of the $\mathrm{TiO}_{2}$ crystallites, the $4 \mathrm{wt} \%$ metal load and a metal particle size of about 7 or $8 \AA$. The in situ sintering experiments
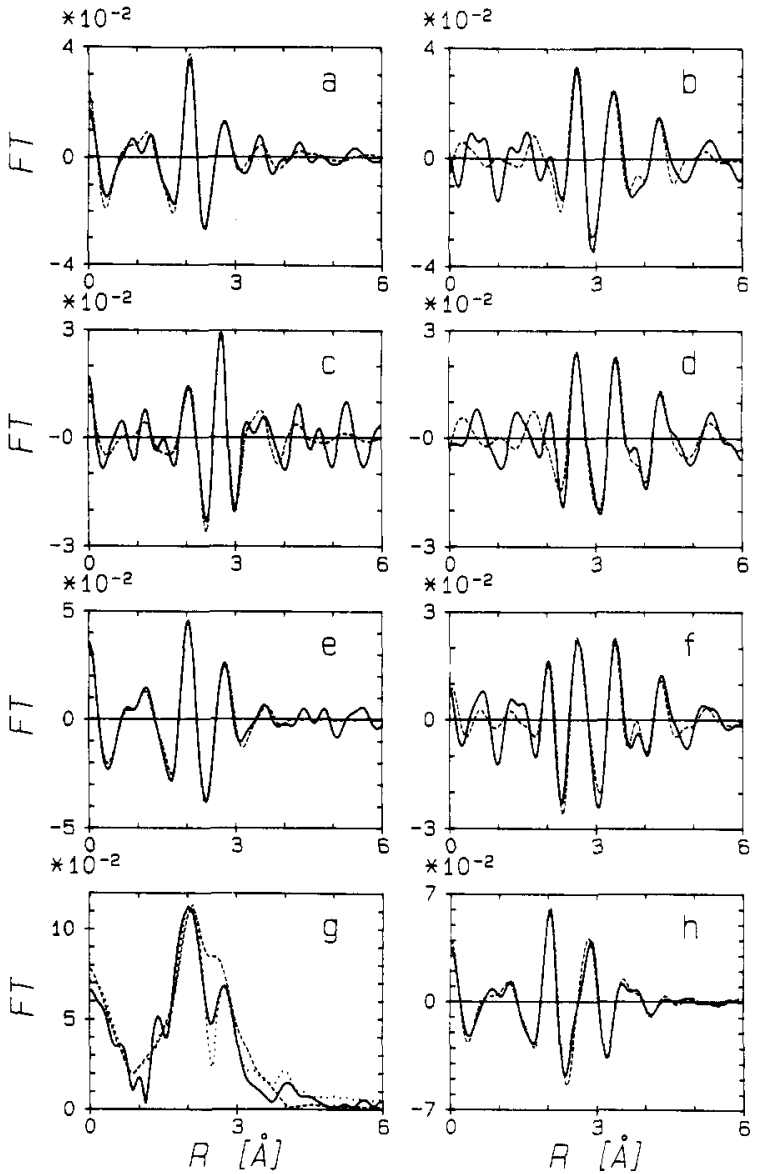

Figure 3. Imaginary parts of the Fourier transforms of the difference spectra (original EXAFS spectra minus the calculated Rh-Rh EXAFS functions, solid lines) and the Fourier transforms of the calculated $\mathrm{Rh}-\mathrm{O}$, Ti EXAFS functions (dashed lines). The Fourier transforms are $k^{1}$ weighted and corrected for Rh-O phase shift. The Fourier transform ranges in $k$ space are indicated in parentheses. (a) $\mathrm{Rh} / \mathrm{TiO}$ after reduction at $473 \mathrm{~K}(2.56-8.73)$; (b) $\mathrm{Rh} / \mathrm{TiO}_{2}$ after reduction at $723 \mathrm{~K}$ (2.95-8.39); (c) $\mathrm{Rh} / \mathrm{Al}_{2} \mathrm{O}_{3}$ after reduction and evacuation at $623 \mathrm{~K}$ (3.46-8.33); (d) $\mathrm{Rh} / \mathrm{TiO}_{2}$ after reduction at $723 \mathrm{~K}$ and evacuation at 623 $\mathrm{K}$ (2.94-8.48); (e) $\mathrm{Rh} / \mathrm{Al}_{2} \mathrm{O}_{3}$ after oxygen exposure at $100 \mathrm{~K}(2.54-$ 8.00); (f) $\mathrm{Rh} / \mathrm{TiO}_{2}$ after oxygen admission at $100 \mathrm{~K}(2.97-8.53) ;(\mathrm{g})$ solid line, $\mathrm{Rh} / \mathrm{Al}_{2} \mathrm{O}_{3}$ after oxygen admission at $300 \mathrm{~K}(2.55-12.45)$ and Fourier transforms of two calculated EXAFS functions; dotted line, $\mathrm{Rh}^{3+}-\mathrm{O}^{2-}+\mathrm{Rh}^{0}-\mathrm{Rh}^{0}$; dashed line, $\mathrm{Rh}^{3+}-\mathrm{O}^{2-}+\mathrm{Rh}^{0}-\mathrm{O}^{2-}$ (see text for further details); (h) $\mathrm{Rh} / \mathrm{TiO}_{2}$ after oxygen exposure at $300 \mathrm{~K}$ (2.87-8.92).

(see Figure 6) indicate that indeed the major part of the metal particles is visible. During sintering by exposing the catalyst to an intense electron beam, large rhodium metal particles were formed. The $d$ spacings in these particles indicated that all metal particles were fcc rhodium; alloy particles in which $\mathrm{Rh}$ and $\mathrm{Ti}$ are ordered $\left(\mathrm{RhTi}_{3}, \mathrm{RhTi}\right.$ or $\left.\mathrm{Rh}_{3} \mathrm{Ti}\right)$ have not been observed. The same sintering experiments on $\mathrm{TiO}_{2}$ supported $\mathrm{Ir}$ catalysts resulted in $\mathrm{Ir}_{3} \mathrm{Ti}$ alloy formation. Clearly, for rhodium catalysts, alloy formation in the SMSI state is unlikely to occur.

During the HRTEM experiments, several $\mathrm{Rh} / \mathrm{TiO}{ }_{2}$ catalysts were studied extensively after reduction at high temperature. In these experiments no sign of even the slightest coverage has been found. Image calculations ${ }^{31}$ show that a monolayer of $\mathrm{TiO}_{x}$ on top of a rhodium particle containing five rhodium atoms should be visible. The visibility depends on the defocus of the microscope, the atomic configuration of the monolayer, and the thickness and orientation of the support. Before the sample is transferred to the microscope, the sample will always be passivated. On larger rhodium particles (other $\mathrm{Rh} / \mathrm{TiO}_{2}$ catalysts have been investigated as well) islands of $\mathrm{TiO}_{x}$ will be formed on top of the metal particles during passivation. Since these islands will be several atomic layers

(31) Zandbergen, H. W.; Martens, J. H. A., to be published. 

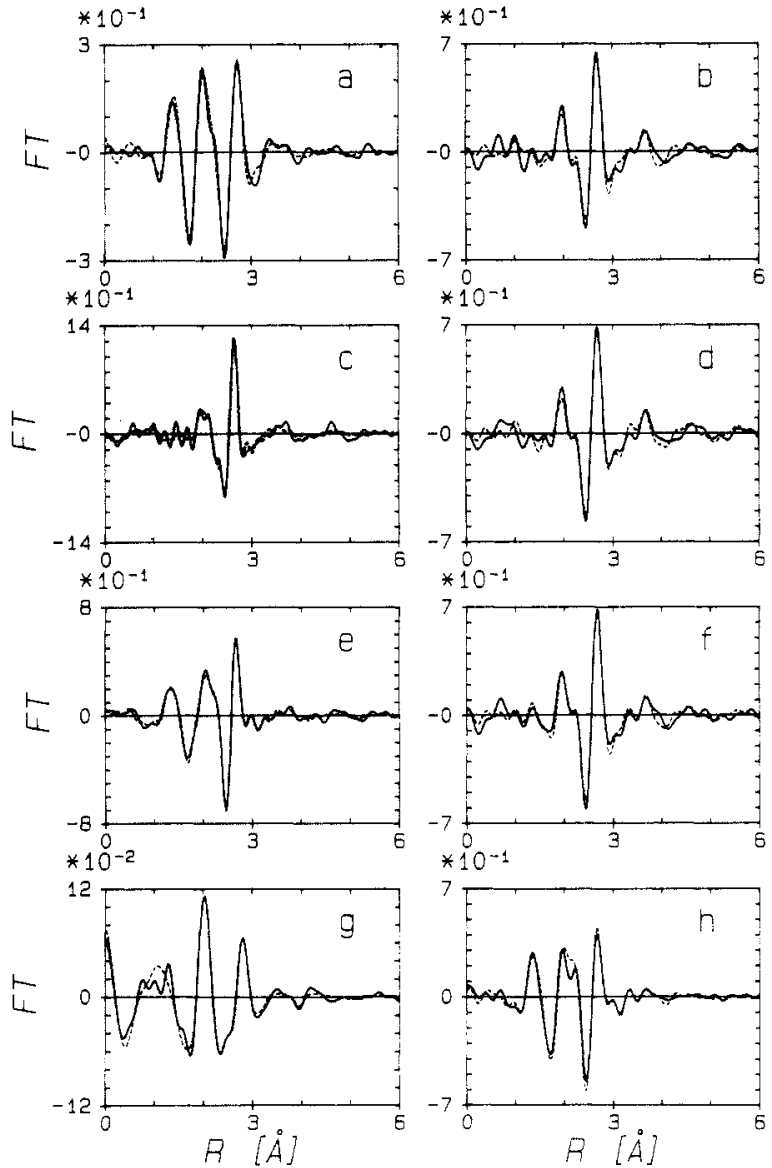

Figure 4. Imaginary parts of the Fourier transform of the original EXAFS spectra (solid lines) and calculated best fitting EXAFS spectra (using the parameters presented in Table II. The Fourier transforms are $k^{1}$-weighted and corrected for $\mathrm{Rh}-\mathrm{Rh}$ phase shift and backscattering amplitude. The Fourier transform ranges in $k$ space are indicated in parentheses. (a) $\mathrm{Rh} / \mathrm{TiO}_{2}$ after reduction at $473 \mathrm{~K}(3.33-10.24)$; (b) $\mathrm{Rh} / \mathrm{TiO}_{2}$ after reduction at $723 \mathrm{~K}(2.82-10.13)$; (c) $\mathrm{Rh} / \mathrm{Al}_{2} \mathrm{O}_{3}$ after reduction and evacuation at $623 \mathrm{~K}(2.97-14.58)$; (d) $\mathrm{Rh} / \mathrm{TiO}$ after reduction at $723 \mathrm{~K}$ and evacuation at $623 \mathrm{~K}(2.85-10.06) ;(\mathrm{e}) \mathrm{Rh} / \mathrm{Al}_{2} \mathrm{O}_{3}$ after oxygen exposure at $100 \mathrm{~K}(3.26-12.03) ;(\mathrm{f}) \mathrm{Rh} / \mathrm{TiO}_{2}$ after oxygen admission at $100 \mathrm{~K}(2.84-10.06) ;(\mathrm{g}) \mathrm{Rh} / \mathrm{Al}_{2} \mathrm{O}_{3}$ after oxygen admission at $300 \mathrm{~K}(2.55-12.45) ;(\mathrm{h}) \mathrm{Rh} / \mathrm{TiO}_{2}$ after oxygen exposure at $300 \mathrm{~K}$ (3.22-10.18)

thick, they must be visible with HRTEM. Although investigations were performed to image these in particular, such islands were never observed. In conclusion, we feel that coverage is unlikely to occur for $\mathrm{Rh} / \mathrm{TiO}_{2}$ catalysts.

In Figure 7 it is shown that the crystallographic surface plane exposed most is evidently the [101] crystal face. Other planes exposed are [001] and [103]. In Figure 7 an example is given. The particles on these micrographs are found mainly on edges of the $\mathrm{TiO}_{2}$ crystallites and on [101] crystal faces; only a few particles were found on [001] crystal faces.

\section{Discussion}

1. $\mathrm{Rh} / \mathrm{TiO}_{2}$ after Reduction at $473 \mathrm{~K}$. After reduction at 473 $\mathrm{K}$ and cooling down under $\mathrm{H}_{2}$, the average $\mathrm{Rh}-\mathrm{Rh}$ coordination number is 2.5 (Table II), demonstrating that the metal particles were highly dispersed. The $\mathrm{Rh}-\mathrm{Rh}$ distance was found to be equal to the $\mathrm{Rh}-\mathrm{Rh}$ bulk distance, $2.687 \AA$. In addition to rhodium nearest neighbors, two different rhodium-oxygen contributions could be discerned. These contributions arise from approximately 1.3 oxygens at $2.07 \AA$ and 1.0 oxygen at $2.78 \AA$. The first $R h-O$ distance is only slightly longer than the $\mathrm{Rh}^{3+}-\mathrm{O}^{2-}$ distance in bulk $\mathrm{Rh}_{2} \mathrm{O}_{3}(2.05 \AA)$. This indicates that reduction was incomplete and that part of the rhodium was still in the calcined, oxidized state. This might seem to contradict our TPR results, which indicated that reduction was complete at $400 \mathrm{~K}$. There is, however, a slight difference between the two reduction treatments. In TPR,
TABLE II: Final Results from EXAFS Data Analysis ${ }^{a}$

\begin{tabular}{|c|c|c|c|c|c|}
\hline treatment & $\mathrm{NN}$ & coord no. ${ }^{b}$ & distance, ${ }^{b} \AA$ & $\begin{array}{c}\Delta \sigma^{2}, b, c \\
10^{-3} \AA^{-2}\end{array}$ & $E_{0},{ }^{b, c} \mathrm{eV}$ \\
\hline \multirow{3}{*}{ R473 } & $\mathrm{Rh}$ & $\begin{array}{r}1 \\
2.5(0.2)\end{array}$ & $\begin{array}{l}\mathrm{Rh} / \mathrm{TiO}_{2} \\
2.687(0.005)\end{array}$ & $8(1)$ & $2.6(1)$ \\
\hline & $\mathrm{O}$ & $1.3(0.4)$ & $2.075(0.01)$ & $2(1)$ & \\
\hline & 0 & 1.0( & $2.78(0.01)$ & $2(1)$ & $-7(2)$ \\
\hline \multirow[t]{4}{*}{ R473-R723 } & $\mathrm{Rh}$ & $3.4(0.2)$ & $2.634(0.005)$ & $1.6(1)$ & $7.5(1)$ \\
\hline & 0 & $1.9(0.3)$ & $2.60(0.01)$ & $7(2)$ & $-2(1)$ \\
\hline & $\mathrm{Ti}$ & & 3.4 & & $10(2)$ \\
\hline & $\mathrm{Ti}$ & & & & $10(2)$ \\
\hline \multirow{4}{*}{$\begin{array}{l}\text { R473-R723- } \\
\text { E623 }\end{array}$} & $\mathrm{Rh}$ & $3.4(\mathrm{C}$ & 2.646 & $1(1)$ & $3.8(1)$ \\
\hline & 0 & $1.8(0.3)$ & & $9(2)$ & $-2.0(1)$ \\
\hline & $\mathrm{Ti}$ & & & & \\
\hline & $\mathrm{Ti}$ & & & & 10 \\
\hline \multirow{5}{*}{$\begin{array}{l}\text { R723-E623- } \\
\text { O100 }\end{array}$} & $\mathrm{Rh}$ & & & & $5.1(1)$ \\
\hline & 0 & 1.0 & & 6.5 & $-5(1)$ \\
\hline & $\mathrm{O}$ & & & & $-5(1)$ \\
\hline & $\mathrm{Ti}$ & & & & 8 \\
\hline & $\mathrm{Ti}$ & & & 4.5 & $10(2)$ \\
\hline \multirow{5}{*}{$\begin{array}{l}\text { R723-E623- } \\
\text { O100- } \\
\text { O300 }\end{array}$} & $\mathrm{Rh}$ & $3.4(0.2)$ & 2.6 & $2.9(2)$ & $2.4(2)$ \\
\hline & 0 & $2.2(0.3)$ & & $6.5(2)$ & $-3(2)$ \\
\hline & 0 & 1.5 & & 9.8 & $5(2)$ \\
\hline & $\mathrm{Ti}$ & & & 1.2 & $10(3)$ \\
\hline & $\mathrm{Ti}$ & $1.4(0.4)$ & $4.36(0.05)$ & $4.5(2)$ & $10(3)$ \\
\hline \multirow{4}{*}{ R623-E623 } & & & & & \\
\hline & $\mathrm{Rh}$ & $0.2)$ & 2.6 & 3( & 1.7( \\
\hline & $\mathrm{O}$ & & & $1(2)$ & $8.4(2)$ \\
\hline & 0 & $2.0(0.2)$ & $2.73(0.01)$ & $2.5(1)$ & $-4.1(2)$ \\
\hline \multirow{3}{*}{$\begin{array}{l}\text { R623-E623- } \\
\text { O100 }\end{array}$} & $\mathrm{Rh}$ & $4.1(0.2)$ & 2.63 & $3.4(1)$ & $7.9(1)$ \\
\hline & 0 & & & $1(2)$ & $-2.5(1)$ \\
\hline & $\mathrm{O}$ & $1.4(0.2)$ & & $2.5(1)$ & $-2.9(1)$ \\
\hline R623-E623- & $\mathrm{Rh}$ & $1.9(0.3)$ & $2.645(0.01)$ & $4.4(2)$ & $4(2)$ \\
\hline pino & $\mathrm{O}$ & $3.6(0.3)$ & & $4.7(2)$ & $-0.5(2)$ \\
\hline O300 & $\mathrm{O}$ & $1.7(0.3)$ & $2.76(0.03)$ & $6(3)$ & $4(2)$ \\
\hline
\end{tabular}

${ }^{a} \mathrm{R}$ reduction in $\mathrm{H}_{2}$ at the temperature indicated. $\mathrm{E}=$ evacuation at the temperature indicated. $\mathrm{O}=$ admission of oxygen at the temperature indicated. ${ }^{b}$ Estimated overall (experimental + systematic) error is given in parentheses. ${ }^{\circ} \Delta \sigma^{2}$, the Debye-Waller factor, is a measure for the disorder and $E_{0}$ is a correction on the edge position; see ref 29 for more details.

the $\mathrm{H}_{2}$ mixture is forced to flow through the catalyst bed, whereas in the in situ EXAFS cell $\mathrm{H}_{2}$ flows along and not through the self-supporting sample wafer. Thus, in TPR the removal of water out of the catalyst bed is by convection and consequently much faster than during the in situ reduction in the EXAFS cell, where water is removed only by diffusion. In the EXAFS cell, therefore, reduction may take longer to complete. In our earlier paper, ${ }^{23}$ we found that the catalyst was completely reduced after reduction at $473 \mathrm{~K}$. This can readily be explained by the lower heating rate ( $2.5 \mathrm{~K} \mathrm{~min}^{-1}$ vs $5 \mathrm{~K} \mathrm{~min}^{-1}$ ) and the longer reduction treatment ( $2 \mathrm{~h}$ vs $0.5 \mathrm{~h}$ ) used in our earlier study.

Reduction of supported noble metal oxide particles is known to be a fast process, limited only by nucleation and not by particle size. ${ }^{25}$ As a consequence, once the reduction of an oxide particle has started (nucleation) the reduction process is rapidly completed. We expect the particles to be either fully metallic or fully oxidized. Therefore, in the catalyst reduced at $473 \mathrm{~K}$, metal particles as well as oxide particles will exist. Since the information in EXAFS is averaged over all rhodium atoms and ions present in the sample, the actual $\mathrm{Rh}-\mathrm{Rh}$ coordination number for the rhodium atoms in the metal particles is higher than the measured coordination number. ${ }^{32}$ We will assume that the $\mathrm{Rh}-\mathrm{O}$ coordination number in the oxide particles is 6 , the same as in bulk $\mathrm{Rh}_{2} \mathrm{O}_{3}{ }^{32}$ This assumption is reasonable, even for small oxide particles, since $\mathrm{Rh}^{3+}$ ions may have $\mathrm{O}^{2-}$ ions from the support as one or more of the six oxygen nearest neighbors. The fraction of rhodium present in the oxidic form is then $1.3 / 6=0.22$ and the fraction of rhodium atoms in the metal particles is 0.78 . This means that the actual

(32) Koningsberger, D. C.; van Zon, J. B. A. D.; van't Blik, H. F. J.; Visser, G. J.; Prins, R.; Mansour, A. N.; Sayers, D. E.; Short, D. R.; Katzer, J. R. J. Phys. Chem. 1985, 89, 4075 


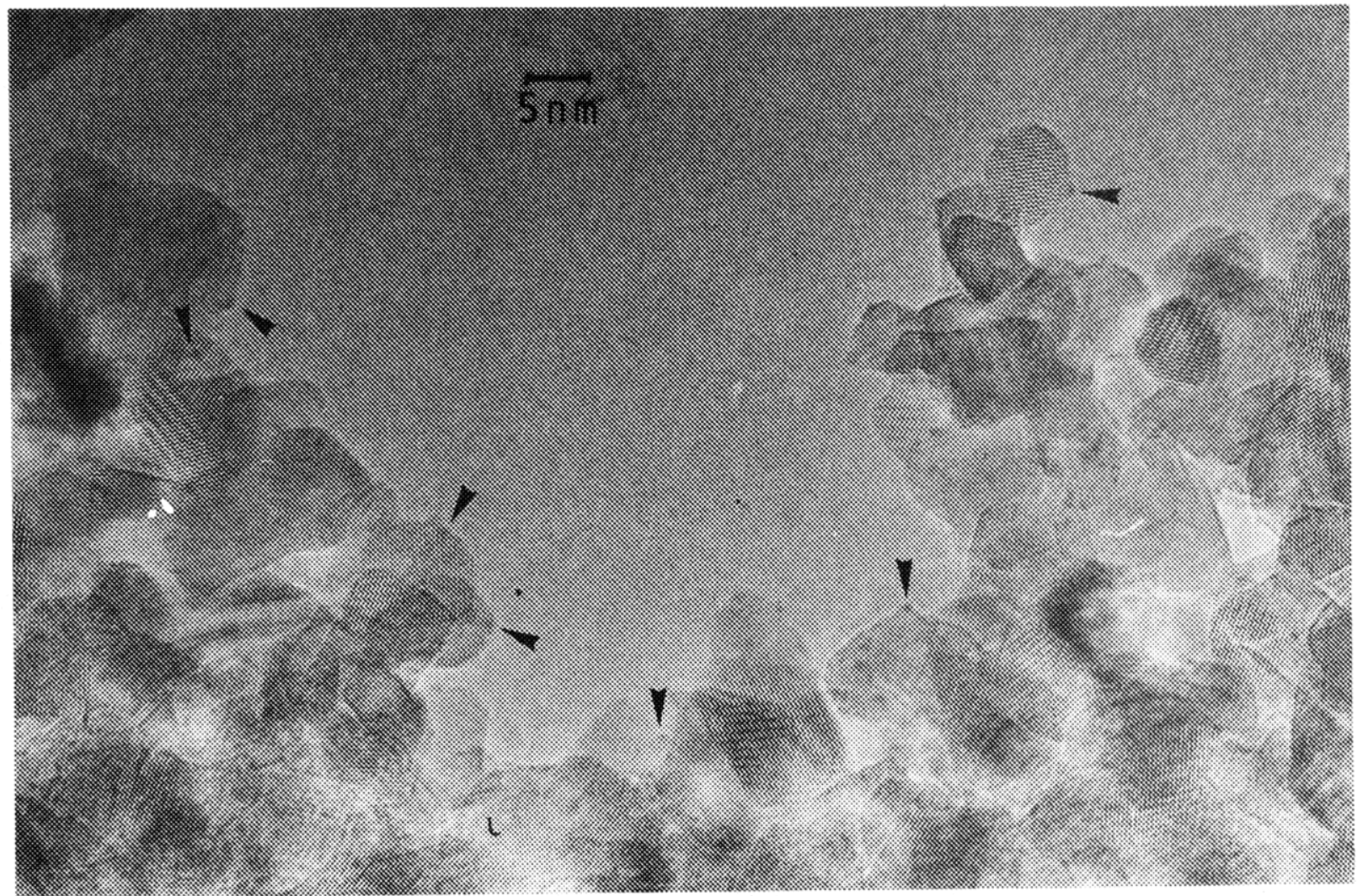

Figure 5. HRTEM micrograph of the $\mathrm{Rh} / \mathrm{TiO}_{2}$ catalyst after reduction at $773 \mathrm{~K}$ and subsequent passivation. The arrows indicate metal particles. The micrograph is taken near Scherzer focus. Therefore, the visibility of the metal particles is not very good, but the uncertainty in their size is best.

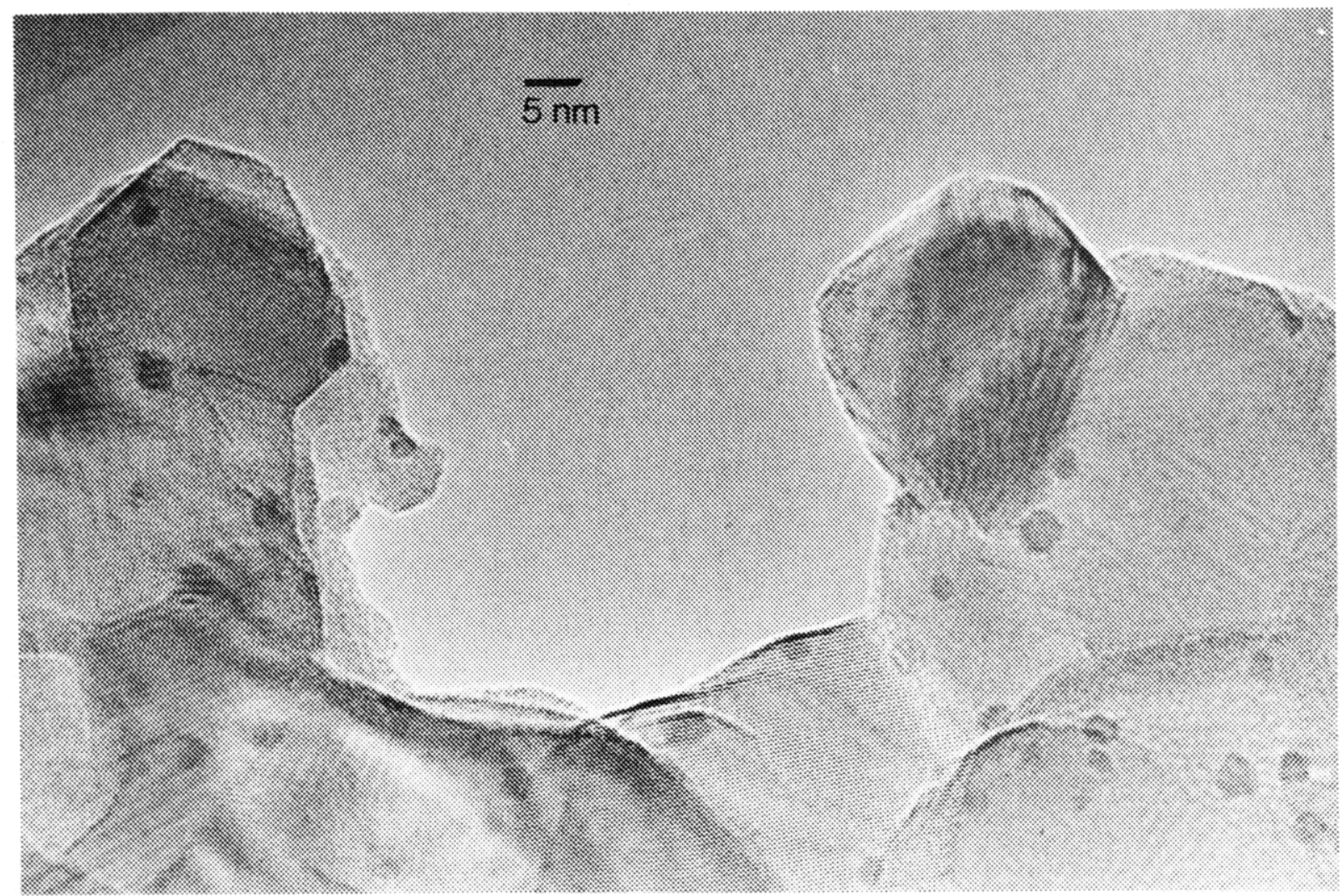

Figure 6. HRTEM micrograph of the $\mathrm{Rh} / \mathrm{TiO}_{2}$ catalyst after reduction at $773 \mathrm{~K}$ and subsequent passivation and in situ sintering.

$\mathrm{Rh}-\mathrm{Rh}$ coordination number for the rhodium atoms in the metal particles is equal to $2.5 / 0.78=3.2$.

As in earlier papers, ${ }^{28,32}$ we ascribe the oxygen neighbors at $2.78 \AA$ to oxygen ions from the supporting oxide. The rhodium atoms in the metal-support interface have oxygen ions from the support as nearest neighbors. The radius of zerovalent rhodium is about $1.34 \AA$, and the radius of divalent oxygen ions is about $1.4 \AA$. One may therefore expect a $\mathrm{Rh}^{0}-\mathrm{O}^{2-}$ distance of about $2.74 \AA$, in good agreement with the reported value of $2.78 \AA$. Since the oxygen ions at $2.78 \AA$ are only nearest neighbors to rhodium atoms in the metallic particles, the $\mathrm{Rh}^{0}-\mathrm{O}^{2-}$ coordination number must be corrected in the same way as we have corrected 


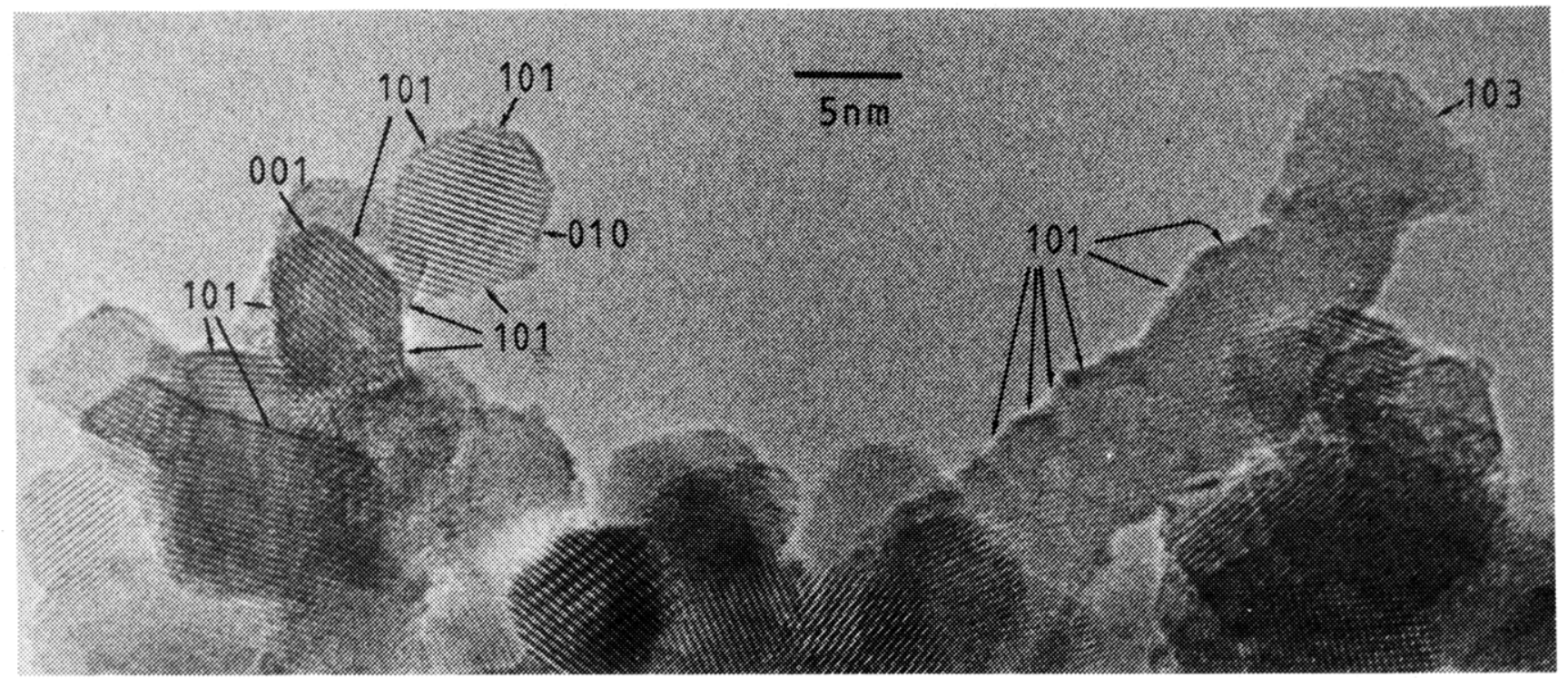

Figure 7. HRTEM micrograph of the $\mathrm{Rh} / \mathrm{TiO}_{2}$ catalyst after reduction at $773 \mathrm{~K}$ and subsequent passivation. Several exposed crystal faces are indicated.

the $\mathrm{Rh}^{0}-\mathrm{Rh}^{0}$ coordination number; the corrected value is $1.0 / 0.78$ $=1.3$. To find the real number of oxygen neighbors for each interfacial rhodium metal atom, this value has to be divided by the fraction of metal atoms in the metal-support interface. ${ }^{28}$

It is often found that background subtraction is difficult in EXAFS spectra of catalysts in which the metal component is (partly) oxidized. Using the cubic spline method, there is no unambiguous criterion for a correct background subtraction. For metallic catalysts, the choice of the smoothing parameter in the cubic spline routine should be such that the magnitude of the Fourier transform in the region below $1 \AA$ is low. For oxidic samples as the present one, this can be achieved, but it is always observed that the first peak in the Fourier transform, in this case the $\mathrm{Rh}^{3+}-\mathrm{O}^{2-}$ contribution has slightly decreased in intensity. The second peak, in general, has not decreased in intensity. Therefore, the $\mathrm{Rh}^{3+}-\mathrm{O}^{2-}$ coordination number will be slightly underestimated and so will be the corrected $\mathrm{Rh}^{0}-\mathrm{Rh}^{0}$ and $\mathrm{Rh}^{0}-\mathrm{O}^{2-}$ coordination numbers. In general, the error will not exceed $20 \%$.

In the analysis described above, we have used the phase shift and backscattering amplitude obtained from $\mathrm{Rh}_{2} \mathrm{O}_{3}$ to calculate the $\mathrm{Rh}^{0}-\mathrm{O}^{2-}$ EXAFS functions. Since in $\mathrm{Rh}_{2} \mathrm{O}_{3}$ the absorberscatterer pair is $\mathrm{Rh}^{3+}-\mathrm{O}^{2-}$ with a coordination distance of 2.05 $\AA$, it is incorrect to use data from $\mathrm{Rh}_{2} \mathrm{O}_{3}$ EXAFS functions to calculate $2.78 \AA \mathrm{Rh}^{0}-\mathrm{O}^{2-}$ EXAFS functions in which the coordination distance is considerably larger and the valence state of one of the members of the absorber-scatterer pair is different. It has been shown ${ }^{28,33}$ that in such cases the calculated distances are reliable. The $\mathrm{Rh}^{0}-\mathrm{O}_{2}^{-}$coordination numbers, however, are underestimated. There is no indication for the degree of underestimation. The actual average $\mathrm{Rh}^{0}-\mathrm{O}^{2-}$ coordination number must therefore be higher than the above reported value of 1.3.

At this point, we are in a position to estimate the size of the metal particles. In Figure 8, examples of four-, five-, seven-, and eight-atom metal particles are shown. In the four-atom metal particle, each metal atom has three direct rhodium nearest neighbors. The average $\mathrm{Rh}-\mathrm{Rh}$ coordination number for this particle therefore is 3.0. In the five-atom metal particle, each interfacial atom has three nearest neighbors, two interfacial atoms, and the top atom. The top atom has four direct nearest neighbors, the four interfacial atoms. The average number of rhodium nearest neighbors in this particle is therefore 3.2 and the average diameter is about $6.5 \AA$. The average coordination number for the seven- and eight-atom metal particles is 4.0 and their diameter is about $8.5 \AA$. Since the observed $R h-R h$ coordination number is about $3.4 \pm 0.3$, we conclude that the metal particles in the a
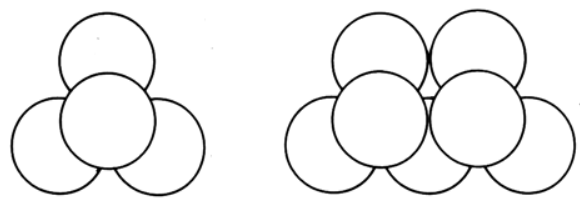

C

b
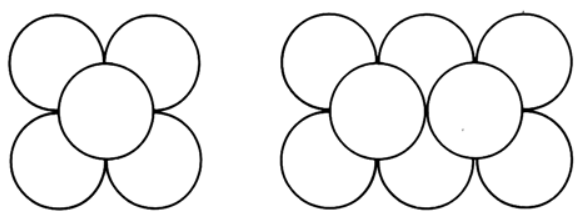

d

Figure 8. Small metal particles: (a) four-atom metal particle, (b) fiveatom metal particle, (c) seven-atom metal particle, (d) eight-atom metal particle.

$\mathrm{Rh} / \mathrm{TiO}_{2}$ catalyst contain roughly five or six metal atoms. The results of the HRTEM characterization, a very uniform and narrow particles size distribution around $7 \AA$, are in good agreement with this conclusion. Obviously, even for very small metal particles, the EXAFS coordination number very accurately determines the metal particle size. These results, however, leave some room for discussion about a particle size distribution. The EXAFS results give a $\mathrm{Rh}-\mathrm{Rh}$ coordination number of $3.4 \pm 0.3$. This corresponds to metal particles containing from four up to six or seven or even eight atoms. The particle diameter determined with HRTEM is about $7.5 \pm 1.5 \AA$. This corresponds to metal particles containing roughly three up to about nine atoms per particle. Because the average particle size as determined by both EXAFS and HRTEM points to particles containing about five atoms, we assume the metal particles contain between four and eight metal atoms. The average metal particle will contain five atoms. Even explanations in terms of bimodal size distributions are possible. In that case, a minor part of the $\mathrm{Rh}$ atoms is present in particles containing one or two metal atoms and the major part in larger particles, which contain on the average seven or eight atoms per particle. We believe, however, that the latter situation is unlikely.

2. $\mathrm{Rh} / \mathrm{TiO}_{2}$ after Reduction at $723 \mathrm{~K}$. After reduction at 723 $\mathrm{K}$, we found no evidence for the presence of rhodium oxide particles. Apparently, at this tempertaure the reduction was complete. The $\mathrm{Rh}-\mathrm{Rh}$ coordination number was 3.4 , in good agreement with the corrected (and possibly underestimated) value of 3.2 reported above. This indicates that during the high-temperature reduction no sintering had taken place. The $R h-R h$ coordination distance had decreased markedly. For non-SMSI catalysts such as $\mathrm{Rh} / \mathrm{Al}_{2} \mathrm{O}_{3}$, such a decrease in the $\mathrm{Rh}-\mathrm{Rh}$ distance 
has been observed after reduction and evacuation at high temperature. ${ }^{34}$ After removal of adsorbed hydrogen, the remaining surface metal atoms contract in order to compensate for the loss of hydrogen nearest neighbors. Obviously, since the measurement was performed in an $\mathrm{H}_{2}$ atmosphere at $100 \mathrm{~K}$, the metal particles in the $\mathrm{Rh} / \mathrm{TiO}_{2}$ catalyst after reduction at $723 \mathrm{~K}$ did not chemisorb $\mathrm{H}_{2}$. Clearly, the metal particles were in the SMSI state. In our earlier $\mathrm{Rh} / \mathrm{TiO}_{2}$ study we reported the same observations.

The presence of the long-distance $\mathrm{Rh}-\mathrm{O}$ contribution is as expected. However, the bond length between interfacial rhodium atoms and supporting $\mathrm{O}^{2-}$ ions has decreased from 2.78 to 2.60 $\AA$. The decrease in $\mathrm{Rh}-\mathrm{Rh}$ distance, $0.053 \AA$, indicates a decrease in the average rhodium atomic radius of $0.027 \AA$. This decrease, however, is too small to account for the observed decrease of 0.18 $\AA$ in the $\mathrm{Rh}^{0}-\mathrm{O}^{2-}$ bond. Although it is obvious that this decrease is the result of a change in the metal-support interaction, it is not evident what kind of interaction has caused this decrease. In our earlier study we reported a decrease in the $\mathrm{Rh}^{0}-\mathrm{O}^{2-}$ distance of $0.04 \AA$. That catalyst was reduced at a temperature $50 \mathrm{~K}$ below the reduction temperature of the present catalyst (673 and 723 $\mathrm{K}$, respectively). The metal-support interaction induced by the high-temperature reduction is obviously stronger when the catalyst is reduced at higher temperatures.

In the SMSI state, two additional contributions were detected, titanium neighbors at 3.41 and $4.39 \AA$. These contributions could not be detected after the low-temperature reduction. In our previous paper, ${ }^{23}$ we reported that a $3.4-\AA \mathrm{Rh}-\mathrm{Ti}$ contribution was present after reduction at $673 \mathrm{~K}$. The better signal-to-noise ratio of the present experiments and the enhanced metal-support interaction obviously enable us to distinguish even more contributions. To explain these contributions, we need to take a closer look at the supporting oxide, anatase $\mathrm{TiO}_{2}$. The HRTEM micrographs show that the [101] anatase crystal face is exposed most. HRTEM also showed that the majority of the metal particles was present on the edges of the $\mathrm{TiO}_{2}$ crystallites and the rest of the metal particles was present predominantly on [101] crystal faces. It is therefore not evident what the structure of the (average) crystal face is on which the particles rest. The majority of the crystal faces are [101] faces. It is not unlikely that the crystal face on the edge of the crystallites, between two [101] crystal faces, is indeed a [001] type crystal face. Surface energy calculations have shown that the [001] crystal face is indeed a stable crystal face. $^{35}$ We therefore assume that the metal particles rest on [001] and [101] type crystal faces.

In Figure 9, $a$ and b, both a [001] and [101] anatase crystal face are shown. Both crystal faces consist of a two-dimensional rectangular array of oxygen ions, with as many octahedral sites as oxygen ions. Half of these octahedral sites are occupied by $\mathrm{Ti}^{4+}$ ions. We assume that the five- (or eight)-atom metal particle (see Figure 8) rests on these crystal faces. Figure 9c,d shows the most plausible arrangement for this metal particle on both faces; four metal atoms are interfacial atoms and each interfacial atom has four oxygen nearest neighbors. The average $\mathrm{Rh}^{0}-\mathrm{O}^{2-}$ coordination number in this arrangement is 3.2. Earlier we argued that our method of calculating $\mathrm{Rh}^{0}-\mathrm{O}^{2-}$ coordination numbers underestimates the real $\mathrm{Rh}^{0}-\mathrm{O}^{2-}$ coordination numbers. The apparent discrepancy between the expected and the measured value of 1.9 is therefore acceptable.

In the models we have described, we assumed that in a first approximation the rhodium atoms of the metal particles are situated on lattice-oxygen positions, that is, positions which would have been occupied by oxygen ions if another $\mathrm{TiO}_{2}$ layer had been deposited on the crystal. Therefore, it does not matter whether the metal particles rest on [101] or [001] or any other crystal face. Because the rhodium atoms occupy oxygen-equivalent positions, the $\mathrm{Rh}-\mathrm{O}^{2-}$ distances (and $\mathrm{Rh}^{-\mathrm{Ti}^{n+}}$ distances, these will be discussed later) will be the same, regardless of the crystal face on which the particles rest. The coordination distances are model-

(34) van't Blik, H. F. J.; van Zon, J. B. A. D.; Koningsberger, D. C.; Prins, R. J. Mol. Catal. 1984, 25, 379.

(35) Woning, J.; Santen, R. A. Chem. Phys. Lett. 1983, 101 (6), 541

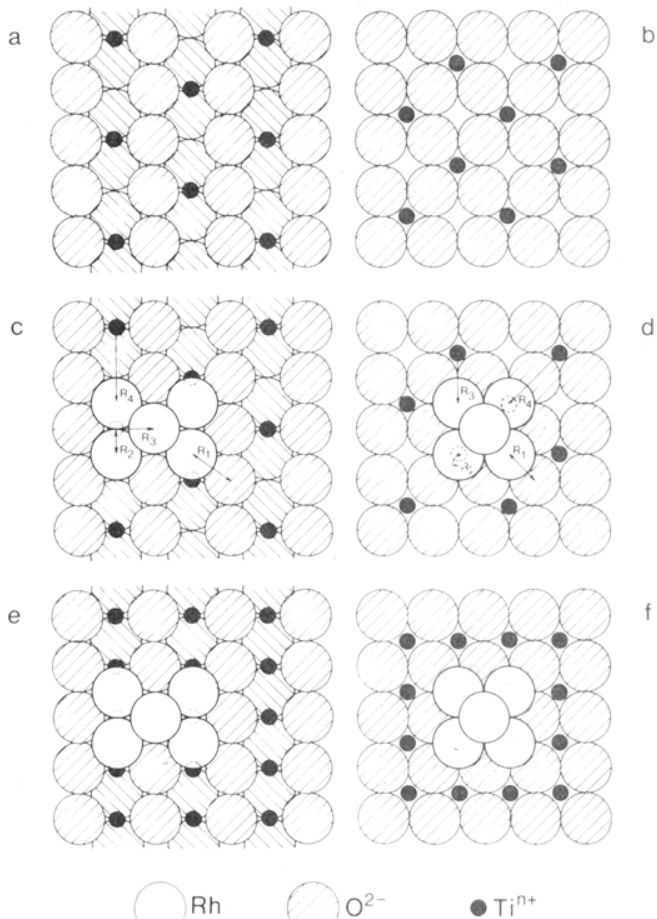

Figure 9. $\mathrm{TiO}_{2}$ crystal faces: (a) [101] anatase crystal face; (b) [001] anatase crystal face; (c) [101] anatase crystal face with a five-atom metal particle; (d) [001] anatase crystal face with a five-atom metal particle; (e) [101] anatase crystal face with a five-atom metal particle after reduction; (f) [001] anatase crystal face with a five-atom metal particle after reduction. $R_{1}=2.7 \AA\left(\mathrm{Rh}^{0}-\mathrm{O}^{2}-\right) ; R_{2}=2.0 \AA\left(\mathrm{Rh}^{0}-\mathrm{Ti}\right) ; R_{3}=3.4$ $\AA\left(\mathrm{Rh}^{0}-\mathrm{Ti}\right) ; R_{4}=4.3 \AA\left(\mathrm{Rh}^{0}-\mathrm{Ti}\right)$.

independent. The coordination numbers, however, may vary, but only slightly. Another consequence of this assumption is that the metal particles grow epitaxially on the supporting oxide, which is not unlikely for very small metal particles. The metal particles in Figure 8a,c, which have been grown epitaxially on [111] type crystal faces, also fit on the [001] and [101] type crystal faces. Thus, the four-, five-, seven-, and eight-atom metal particles in Figure 8 represent possible structures of the metal particles. For the sake of clarity, however, we will focus only on the five-atom metal particle on a [001] or [101] type anatase crystal face. One more detail needs closer attention. Anatase is built of slightly distorted octahedra. As a result, in pure anatase, two $\mathrm{O}^{2-}-\mathrm{O}^{2-}$ distances are encountered. If the $\mathrm{Rh}$ atoms are situated on $\mathrm{O}$ positions, one should expect the same two $\mathrm{Rh}-\mathrm{O}^{2-}$ distances as well. We found however only one $\mathrm{Rh}-\mathrm{O}^{2-}$ distance. This can be accounted for as follows. In the [101] plane (see Figure 9a), the lower $\mathrm{O}^{2-}$ ions, the ions underneath a $\mathrm{Ti}^{4+}$ ion, are shifted alternately slightly to the right and slightly to the left with respect to their position as shown in Figure 9a. This has very little influence on the $\mathrm{Rh}-\mathrm{O}^{2-}$ distances because the displacement is perpendicular to the distance. For metal particles situated on [101] type crystal faces we thus expect only one $\mathrm{Rh}-\mathrm{O}^{2-}$ distance with possibly a increased disorder around that distance. From Table II, it is indeed clear that the disorder in the $\mathrm{Rh}^{0}-\mathrm{O}^{2-}$ distances is larger than any other disorder (note that the disorder is expressed relative to the disorder in the reference compounds). The $\mathrm{O}^{2-}$ ions in the [001] plane (see Figure $9 \mathrm{~b}$ ) are situated alternately a little above and a little underneath the horizontal plane. We assume that the outermost [001] plane of $\mathrm{O}^{2-}$ ions has relaxed in such a way that all $\mathrm{O}^{2-}$ ions are in the same plane. In that case we once more expect only one $\mathrm{Rh}-\mathrm{O}^{2-}$ distance with possibly an increased disorder.

A closer look at our model in Figure 9 reveals three $\mathrm{Rh}^{0}-\mathrm{Ti}^{4+}$ distances: $R_{2}=2.1, R_{3}=3.4$, and $R_{4}=4.3 \AA$. The average coordination numbers for these contributions are respectively 0.4 , 1.6, and 3.2. (The latter coordination number is higher than one might derive from Figure 9. In Figure 9, however, only the $\mathrm{Ti}^{4+}$ ions in the top layer are shown. $\mathrm{The}^{\mathrm{Ti}}{ }^{4+}$ ions in the second layer 
will also contribute to the $4.3-\AA \mathrm{Rh}^{0}-\mathrm{Ti}^{4+}$ contribution. Another "hidden" $4.3 \AA \mathrm{Rh}^{0}-\mathrm{Ti}^{4+}$ contribution arises from the top rhodium atom in the five metal atom particle and the $\mathrm{Ti}^{4+}$ ion directly underneath the top atom). These coordination numbers are low and one would expect their contributions, especially for the longer distance, not to be detectable by EXAFS. The EXAFS amplitude is in a first approximation inversely proportional to the square of the distance. The values of $N / R^{2}$ for the three contributions are $0.09,0.15$, and 0.16 , respectively. Because of the DebyeWaller factor, however, these values will change. For comparison, $N / R^{2}$ for the $\mathrm{Rh}^{0}-\mathrm{O}^{2-}$ contribution is 0.44 . Since the backscattering amplitudes for the $\mathrm{Rh}-\mathrm{Ti}$ and $\mathrm{Rh}-\mathrm{O}$ contributions do not differ much in magnitude (the $\mathrm{Ti}$ backscattering amplitude is slightly larger), it is evident that the $\mathrm{Rh}^{0}-\mathrm{Ti}^{4+}$ contributions will be hard to detect, compared to the $\mathrm{Rh}^{0}-\mathrm{O}^{2-}$ contribution. Because of the Debye-Waller factor, the $3.4-\AA$ contribution is expected to be the most dominant of the three $\mathrm{Rh}^{0}-\mathrm{Ti}^{4+}$ contributions. In Figure 3a, the difference spectrum for the $473 \mathrm{~K}$ reduced catalyst, a small contribution around $3.4 \AA$ can indeed be observed. But this contribution is too small to allow a reliable analysis.

In our previous paper, we already reported the presence of a 3.4- $\AA \mathrm{Rh}-\mathrm{Ti}^{4+}$ coordination in the SMSI-state catalyst. In the $723 \mathrm{~K}$ reduced sample of the present study, both the $3.4-$ and $4.3-\AA$ $\mathrm{Rh}-\mathrm{Ti}^{4+}$ contributions are indeed observed, but the coordination numbers are higher than anticipated. The explanation for the enhanced presence of these $\mathrm{Rh}_{-} \mathrm{Ti}^{4+}$ contributions in the SMSI state can be found in the reducibility of the $\mathrm{TiO}_{2}$ supporting oxide. During the reduction process, oxygen is removed from the $\mathrm{TiO}_{2}$ surface in the form of water. This process is centered around the metal particle, which provides reactive hydrogen atoms and thus catalyzes this reduction process. After a few oxygen ions have been removed, the second [001] or [101] crystal plane becomes exposed. Bare $\mathrm{Ti}^{3+}$ ions from the first (outermost) crystal face remain on top of the $\mathrm{O}^{2-}$ ions of the second plane. This situation is energetically very unstable and these $\mathrm{Ti}^{3+}$ ions will migrate to empty octahedral sites in the second oxygen layer and possibly the third or even further crystal planes. What we see here is the formation of a $\mathrm{TiO}_{x}$ suboxide and especially the formation of part of a shear plane. The five-atom metal particle is positioned in the same way on the second crystal planes as it was on the outermost plane before reduction, but now the interfacial rhodium atoms have more $\mathrm{Ti}^{3+}$ and $\mathrm{Ti}^{4+}$ nearest neighbors at 3.4 and 4.3 $\AA$ (see Figure 9e,f). This increase in $\mathrm{Ti}^{n+}$ nearest neighbors explains our EXAFS results. We thus conclude that, after reduction at high temperature, the metal particles rest on partially reduced $\mathrm{TiO}_{2}$

Our first conclusion from this analysis is that the metal particles are very small indeed. The average rhodium metal particle in the $4 \mathrm{wt} \% \mathrm{Rh} / \mathrm{TiO}_{2}$ catalyst contains about five rhodium atoms. The diameter of these particles is about $6.5 \AA$. This was confirmed by HRTEM. This technique revealed even more information. After exposure of the sample to an intense electron beam, which resembles reduction at high temperature, the metal particles had sintered to large fcc rhodium metal particles; the presence of any ordered alloy of $\mathrm{Rh}$ and $\mathrm{Ti}$ could be ruled out. The same experiments on $\mathrm{Ir} / \mathrm{TiO}_{2}$ resulted in $\mathrm{Ir}_{3} \mathrm{Ti}$ alloy particles. Thus, it is unlikely that in the $\mathrm{Rh} / \mathrm{TiO}_{2}$ catalyst in the SMSI-state alloy formation takes place. This is in accordance with the results reported by Beard and Ross. ${ }^{19}$ They found that upon heating a platinum catalyst supported on carbon and impregnated with $\mathrm{TiCl}_{4}$ $\mathrm{Pt}_{3} \mathrm{Ti}$ alloy particles were formed. For iridium and platinum alloy formation may play a role in the SMSI state, but for rhodium catalysts this is not the case.

Secondly, we found with EXAFS no evidence for coverage, and HRTEM confirmed this. In the HRTEM study, this catalyst and other $\mathrm{Rh} / \mathrm{TiO}_{2}$ catalysts with larger metal particle sizes were studied extensively after reduction at high temperatures and subsequent passivation. In these studies no sign of even the slightest coverage was found. It is known that after passivation and subsequent reduction at low temperature the normal hydrogen adsorption capacity of the metal particles is partly, but not com- pletely, restored. ${ }^{7}$ Therefore, if coverage occurs after reduction at high temperature and suppresses the hydrogen chemisorption by decreasing the exposed metal surface area, passivation will not completely remove the covering oxide. Since in our HRTEM experiments on $\mathrm{Rh} / \mathrm{TiO}_{2}$ catalysts we never observed covering, we conclude that coverage is unlikely to occur for $\mathrm{Rh} / \mathrm{TiO}_{2}$.

In the following we will discuss oxygen adsorption experiments which have been performed in order to investigate whether the metal surface of the rhodium particles in the SMSI state is blocked by a covering $\mathrm{TiO}_{x}$ (sub)oxide. We exposed the catalyst in the in situ cell to pure $\mathrm{O}_{2}$ at $100 \mathrm{~K}$. Before oxygen admission the catalyst had been evacuated at $623 \mathrm{~K}$. Subsequently the temperature was raised to room temperature and another EXAFS spectrum was recorded. We performed the same experiments on a $\mathrm{Rh} / \mathrm{Al}_{2} \mathrm{O}_{3}$ catalyst (reduced at $623 \mathrm{~K}$ ) in order to compare oxygen adsorption properties of rhodium metal particles in the $\mathrm{SMSI}$ state and the normal state $\left(\mathrm{Al}_{2} \mathrm{O}_{3}\right.$ supported $)$. For the sake of clarity, we will discuss alternately the results of the experiments on the $\mathrm{Rh} / \mathrm{Al}_{2} \mathrm{O}_{3}$ and $\mathrm{Rh} / \mathrm{TiO}_{2}$ catalysts.

3. Evacuation at $623 \mathrm{~K}, 3 \mathrm{a} . \mathrm{Rh} / \mathrm{Al}_{2} \mathrm{O}_{3}$. After reduction and evacuation of the $\mathrm{Rh} / \mathrm{Al}_{2} \mathrm{O}_{3}$ catalyst, the major contribution is from rhodium neighbors with a $\mathrm{Rh}-\mathrm{Rh}$ coordination number of 5.6. This indicates that the metal particles contain about 15 atoms and are roughly $10 \AA$ in diameter. ${ }^{24}$ Compared to the bulk value, the $\mathrm{Rh}-\mathrm{Rh}$ coordination distance has decreased by $0.052 \AA$. As we have described in the foregoing this contraction is the result of the evacuation procedure. Because of the removal of adsorbed hydrogen the surface metal atoms contract in order to compensate for the loss of neighbors. $\mathrm{A} \mathrm{Rh}^{0}-\mathrm{O}^{2-}$ contribution is also present, originating from neighboring $\mathrm{O}^{2-}$ ions in the metal-support interface. The small contribution at $2.06 \AA$ has to be ascribed to the presence of rhodium oxide. The maximum temperature during the reduction treatment $(623 \mathrm{~K})$ was high enough to obtain complete reduction of the $\mathrm{Rh} / \mathrm{Al}_{2} \mathrm{O}_{3}$ catalyst. ${ }^{28}$ However, it is possible that partial oxidation has taken place due to formation of water during the evacuation procedure or because of a small leakage during or after the evacuation treatment.

3b. $\mathrm{Rh} / \mathrm{TiO}_{2}$. After reduction at $723 \mathrm{~K}$ of a fresh $\mathrm{Rh} / \mathrm{TiO}_{2}$ sample followed by evacuation at $623 \mathrm{~K}$, the EXAFS spectrum (in $k$ space as well in $r$ space after Fourier transformation) resembles very closely the EXAFS spectrum measured directly after reduction. All differences are within the indicated experimental errors. The $\mathrm{Rh}-\mathrm{Rh}$ distance is still significantly smaller than the bulk value $(2.687 \AA)$ and almost equal to the $\mathrm{Rh}-\mathrm{Rh}$ distance in the evacuated $\mathrm{Rh} / \mathrm{Al}_{2} \mathrm{O}_{3}$ catalyst. Thus, we have confirmed that in the SMSI state the rhodium metal particles do not adsorb $\mathrm{H}_{2}$.

4. Oxygen Admission at $100 \mathrm{~K} .4 a, \mathrm{Rh} / \mathrm{Al}_{2} \mathrm{O}_{3}$. After admission of $\mathrm{O}_{2}$ to the $\mathrm{Rh} / \mathrm{Al}_{2} \mathrm{O}_{3}$ catalyst at $100 \mathrm{~K}$, the EXAFS spectrum changed drastically. The $\mathrm{Rh}-\mathrm{Rh}$ contribution diminished, as is clearly reflected in the decreased amplitude of the EXAFS function at higher $k$ values $\left(k>7 \AA^{-1}\right.$, see Figure 1e). Obviously, after $\mathrm{O}_{2}$ admission at this temperature all the metal particles are partially oxidized. This situation is different from the partially reduced $\mathrm{Rh} / \mathrm{TiO}_{2}$ catalyst, where some of the particles are already fully reduced and others were still oxidized. It is impossible to calculate the size of the remaining metal kernel because now this metallic kernel is covered with $\mathrm{Rh}_{2} \mathrm{O}_{3}$ or possibly another form of rhodium oxide and the $\mathrm{Rh}^{3+}-\mathrm{O}^{2-}$ coordination number in the covering shell of oxide will be different from six. At lower $k$ values, the influence of the pronounced presence of the two $\mathrm{Rh}-\mathrm{O}$ contributions is obvious. These qualitative conclusions are confirmed by the quantitative analysis (cf. Table II). The decrease in the $\mathrm{Rh}-\mathrm{Rh}$ coordination number and the increase of the $\mathrm{Rh}^{3+}-\mathrm{O}^{2-}$ coordination number indicate that the oxidation process has started. Note, that the high- $k$-value part of the EXAFS function is very sensitive for changes in the $R h-R h$ contribution (i.e., average metal particle size) and the low- $k$-value part is sensitive for low- $Z$ scatterer contributions.

4b. $\mathrm{Rh} / \mathrm{TiO}_{2}$. The results for the $\mathrm{Rh} / \mathrm{Al}_{2} \mathrm{O}_{3}$ catalyst presented above are in sheer contrast to the results for oxygen admission to the $\mathrm{Rh} / \mathrm{TiO}_{2}$ catalyst. At higher $k$ values, the EXAFS spectrum 
of the $\mathrm{Rh} / \mathrm{TiO}_{2}$ catalyst after $\mathrm{O}_{2}$ admission at $100 \mathrm{~K}$ resembles very closely the spectra of the reduced and the evacuated samples (cf. Figure 1, $\mathrm{d}$ and $\mathrm{f}$ ). No changes in the $\mathrm{Rh}^{0}-\mathrm{Rh}^{0}$ parameters could be detected. Obviously, for the $\mathrm{Rh} / \mathrm{TiO}_{2}$ catalyst, the basic structure of the metal particles remained intact and oxidation has not taken place. At lower $k$ values there are small differences. This becomes clear from the Fourier transform of the difference spectrum, Figure 3f. Apart from the $\mathrm{Rh}-\mathrm{O}$ and $\mathrm{Rh}-\mathrm{Ti}$ contributions discussed before, a $\mathrm{Rh}-\mathrm{O}$ contribution at $2.09 \AA$ is clearly visible with a coordination number of 1.0 . This $\mathrm{Rh}-\mathrm{O}$ contribution must be different, however, from that of the sample reduced at $423 \mathrm{~K}$. In the EXAFS spectrum of that sample, the $2.06 \AA \mathrm{Rh}-\mathrm{O}$ contribution was assigned to $\mathrm{Rh}^{3+}-\mathrm{O}^{2-}$ absorber-scatterer pairs, present in $\mathrm{Rh}_{2} \mathrm{O}_{3}$ particles. But in the spectrum taken after oxygen admission (cf. Figure 1f) no differences with the spectrum taken after evacuation (Figure 1d) can be observed at $k>6 \AA^{-1}$. In this region, EXAFS is very sensitive to changes in the $R h-R h$ contribution; therefore, neither the $\mathrm{Rh}-\mathrm{Rh}$ coordination number nor the metal particle size has changed. The results of the detailed data analysis confirm this (see Table II). Clearly, oxidation of the rhodium particles on the $\mathrm{TiO}_{2}$ support has not taken place. The only possibility left is to ascribe the $2.09-\AA \mathrm{Rh}-\mathrm{O}$ contribution to oxygen adsorbed on the surface of the metal particles. The atomic radius of zerovalent rhodium in the metal particles is $2.64 / 2$ $=1.32$ and the radius of covalent oxygen is about 0.73 . The expected $R h^{0}-\mathrm{O}^{0}$ distance $(2.05 \AA)$ is in good agreement with the calculated distance of $2.09 \AA$.

A very important result of this analysis is that the metal particles in the SMSI state are capable of adsorbing oxygen. In order to be able to adsorb oxygen, the metal particles must be bare, uncovered, or at least not fully covered with a $\mathrm{TiO}_{x}$ suboxide. Even though oxygen was able to adsorb on the metal particles, oxidation did not take place, in contrast to the $\mathrm{Rh} / \mathrm{Al}_{2} \mathrm{O}_{3}$ catalyst. This suppressed oxidation can only be the result of an electronic influence from the $\mathrm{TiO}_{x}$ suboxide.

5. Oxygen Admission at $300 \mathrm{~K} .5 \mathrm{a} . \mathrm{Rh} / \mathrm{Al}_{2} \mathrm{O}_{3}$. After oxygen admission at $100 \mathrm{~K}$, the $\mathrm{Rh} / \mathrm{Al}_{2} \mathrm{O}_{3}$ catalyst was warmed up to room temperature. The EXAFS spectrum (Figure $1 \mathrm{~g}$ ) differed completely from the spectra of the $\mathrm{Rh} / \mathrm{Al}_{2} \mathrm{O}_{3}$ catalyst after evacuation and oxygen admission at $100 \mathrm{~K}$ (Figure lc,e). At high $k$ values, almost no high- $Z$ scatterer EXAFS is visible, while at low $k$ values, the low- $Z$ scatterer contribution differs markedly from the low- $k$-value part of the two preceding spectra. The main reason for this is a decrease in the $\mathrm{Rh}-\mathrm{Rh}$ coordination number and an increase in the oxidic $\mathrm{Rh}^{3+}-\mathrm{O}^{2-}$ contribution. Because of the high $\mathrm{Rh}^{23}-\mathrm{O}^{2-}$ contribution, the analysis of this spectrum was different from the procedure as described above. The major contribution to the spectrum originated from oxygen scatterers and therefore a $k^{1}$-weighted $\mathrm{Rh}-\mathrm{O}$ phase corrected Fourier transform rather than a $k^{3}$-weighted $\mathrm{Rh}-\mathrm{Rh}$ phase and backscattering corrected Fourier transform was used to calculate the different contributions in the EXAFS spectrum. Since in this Fourier transform an incorrect phase shift function has been used for the (small) $\mathrm{Rh}^{0}-\mathrm{Rh}^{0}$ contribution, the accompanying $\mathrm{Rh}-\mathrm{Rh}$ peak is shifted and coincides with the peak originating from the $\mathrm{Rh}^{0}-\mathrm{O}^{2-}$ bond of about $2.76 \AA$. The fact that the peak at the righ-hand side of the $\mathrm{Rh}^{3+}-\mathrm{O}^{2-}$ contribution is indeed the result of two $\left(\mathrm{Rh}^{0}-\mathrm{Rh}^{0}\right.$ and $\left.\mathrm{Rh}^{0}-\mathrm{O}^{2-}\right)$ contributions is indicated if Figure $3 \mathrm{~g}$, in which the magnitude of the Fourier transform of the original data and of the Fourier transforms of the calculated EXAFS spectra of $\mathrm{Rh}^{3+}-\mathrm{O}^{2-}+\mathrm{Rh}^{0}-\mathrm{Rh}^{0}$ and of $\mathrm{Rh}^{3+}-\mathrm{O}^{2-}+\mathrm{Rh}^{0}-\mathrm{O}^{2-}$ are presented. In the Fourier transform of the former calculated EXAFS function, a strong destructive interference is visible in the region between both peaks, in the latter Fourier transform there is a slightly constructive interference. In the same region in the Fourier transform of the original data, there is a slightly destructive interference. Therefore, we must conclude that the right-hand-side peak in Figure $3 \mathrm{~g}$ is the result of the sum of two contributions, namely $\mathrm{Rh}^{0}-\mathrm{Rh}^{0}$ and $\mathrm{Rh}^{0}-\mathrm{O}^{2-}$. In a $k^{1}$-weighted $\mathrm{Rh}-\mathrm{Rh}$ phase and backscattering amplitude corrected Fourier transform, all contributions are separated, but, as mentioned above, this Fourier transform is not suitable to optimize the dominant low- $Z$ scatter contribution. Because of this, the errors in the parameters of the $\mathrm{Rh}-\mathrm{Rh}$ and $\mathrm{Rh}^{0}-\mathrm{O}^{2-}$ contributions used to calculate the best-fitting spectrum are larger than the errors in the same parameters of the other EXAFS spectra of the $\mathrm{Rh} / \mathrm{Al}_{2} \mathrm{O}_{3}$ catalyst.

As argued before (see $\mathrm{Rh} / \mathrm{TiO}_{2}$ after Reduction at $473 \mathrm{~K}$ ), the $\mathrm{Rh}^{3+}-\mathrm{O}^{2-}$ coordination number is not very accurate. The value of 3.6 must be considered as a lower limit. The $R h^{0}-R h^{0}$ and the $\mathrm{Rh}^{0}-\mathrm{O}^{2-}$ coordination numbers on the other hand are more reliable. The $\mathrm{Rh}^{0}-\mathrm{Rh}^{0}$ contribution had diminished markedly, while the contribution of the long-distance $\mathrm{Rh}^{0}-\mathrm{O}^{2-}$ coordination number increased relative to the $\mathrm{Rh}-\mathrm{Rh}$ coordination number. From this we conclude that the remaining metal kernel of the rhodium particles is covered with rhodium oxide. The presence of rhodium oxide on top of the metal particle creates an extra interface in which zerovalent rhodium is in contact with an oxide. In this interface, new $\mathrm{Rh}^{0}-\mathrm{O}^{2-}$ bonds will be present. This proves that EXAFS is capable of detecting coverage. It implies that coverage of titania-supported metal particles in the SMSI state is even more unlikely than we have suggested up to now.

5b. $\mathrm{Rh} / \mathrm{TiO}_{2}$. When the $\mathrm{Rh} / \mathrm{TiO}_{2}$ catalyst after oxygen admission at $100 \mathrm{~K}$ was warmed up to room temperature, the EXAFS spectrum at higher $k$ values still resembled quite closely the spectrum of the sample after evacuation. This indicates that the basic structure of the metal particle size had not changed and that the formation of rhodium oxide had not yet taken place. Detailed analysis confirmed that the $\mathrm{Rh}-\mathrm{Rh}$ coordination number remained constant. Compared to the spectra after evacuation and after oxygen admission at $100 \mathrm{~K}$, the differences in the EXAFS spectrum at lower $k$ values were much more pronounced. The main reason for this is an enhanced influence from the shortdistance $\mathrm{Rh}^{0}-\mathrm{O}^{0}$ contribution. Obviously, since oxidation had still not taken place, the metal particles had adsorbed more oxygen. This will be explained in the following paragraph.

The contributions from the support ions $\left(\mathrm{Ti}^{n+}\right.$ and $\left.\mathrm{O}^{2-}\right)$ all relaxed to longer distances. For the $\mathrm{Rh}^{0}-\mathrm{Ti}^{n+}$ contributions, this may seem to be in contradiction with the indicated error. However, the errors indicated in Table II are overall errors. They are the sum of the experimental error and the systematic error. The experimental error is the result of (in)accuracies during analysis of the data. The systematic error is the result of the procedure of analyzing the data and may be regarded as being equal for comparable contributions. For example, the error (quoted) of 0.03 in the $\mathrm{Rh}^{0}-\mathrm{Ti}^{n+}$ distance of $3.43 \AA$ in the sample after oxygen admission at $100 \mathrm{~K}$ indicates that the real $\mathrm{Rh}^{0}-\mathrm{Ti}^{n+}$ distance has a $95 \%$ probability of being in the range of $3.40-3.46 \AA$. When the two distances are compared, however, the systematic error can be ruled out and only the experimental error should be taken in account. In a good approximation, the experimental error in the $\mathrm{Rh}-\mathrm{Ti}^{n+}$ distances is about $0.01 \AA$. Thus, the $\mathrm{Rh}^{0}-\mathrm{Ti}^{n+}$ distance in the sample after oxygen admission at $300 \mathrm{~K}$ is in fact significantly larger than the distance found after oxygen admission at $100 \mathrm{~K}$. The $\mathrm{Rh}^{0}-\mathrm{O}^{2-}$ contribution relaxed to $2.75 \AA$, which is very close to the $\mathrm{Rh}^{0}-\mathrm{O}^{2-}$ distance for the catalyst in the normal state. The $\mathrm{Rh}^{0}-\mathrm{Ti}^{n+}$ contributions increased to 3.48 and $4.41 \AA$ indicating that the metal-support interaction has weakened. Both $\mathrm{Rh}^{0}-\mathrm{T}^{n+}$ coordination numbers have decreased. The decrease in the coordination number of the 3.48 - $\AA$ contribution is almost within the experimental error, but the decrease in the $4.36-\AA$ $\mathrm{Rh}^{0}-\mathrm{Ti}^{n+}$ contribution is more pronounced. Clearly, $\mathrm{Ti}^{n+}$ ions in the vicinity of the metal particles have disappeared. This indicates that the $\mathrm{TiO}_{x}$ suboxide around the metal particles has started to reoxidize. This is, of course, in agreement with the fact that the metal-support interaction has decreased in strength and the SMSI state has been removed partly and it may explain the fact that the metal particles have adsorbed more oxygen.

6. Different $R h^{0}-T i^{n+}$ Contributions. In the preceding paragraphs, we discussed two $\mathrm{Rh}-\mathrm{Ti}^{n+}$ contributions present in the EXAFS spectra. Based on these findings, on literature data and on HRTEM, we concluded that the rhodium metal particles in $\mathrm{Rh} / \mathrm{TiO}_{2}$ probably rest on anatase [001] and [101] crystal faces. In a model in which a five-atom metal particle rests on a [001] 
or [101] anatase crystal face, the distances found with EXAFS are indeed present. It is evident that EXAFS will not be able to detect the distances longer than $4.4 \AA$. However, the short 2.1- $\AA$ $\mathrm{Rh}-\mathrm{Ti}^{\mathrm{n}}$ distance should be detectable by EXAFS but we have not been able to straightforwardly detect this $\mathrm{Rh}-\mathrm{Ti}^{\mathrm{it}^{n+}}$ contribution. One of the most important reasons is that especially in the normal state, the expected coordination number for this $2.1 \AA$ bond is low. Consider for example the particle on the [001] plane: two rhodium atoms have one $\mathrm{Ti}^{n+}$ neighbor each; the coordination number therefore is $2 / 5=0.4$. We may expect that this coordination number will increase for the metal particle in the SMSI state by a factor of 2 (or less). Thus, the maximum coordination number one may expect for this contribution is 0.8 and therefore still too small to be detectable by EXAFS. See, for example, Figure $3 b, \mathrm{~d}$. The $\mathrm{Rh}^{0}-\mathrm{O}^{2-}$ coordination number is 1.9. This contribution is well above the noise level (about $1 \times 10^{-2}$ ) but decreasing it by a factor 2 brings it already very close to the noise level. Therefore, a $\mathrm{Rh}^{0}-\mathrm{O}^{2-}$ coordination number of 1 would be difficult to detect and even more difficult to analyze. Consequently, a $\mathrm{Rh}^{0}-\mathrm{Ti}^{n+}$ contribution with a coordination number less than about 1 is almost impossible to detect or analyze. However, in the imaginary parts of the Fourier transforms of the difference spectra of the $\mathrm{Rh} / \mathrm{TiO}_{2}$ catalyst in the SMSI state (Figure 3b,d) small deviations between theory and experiment are visible around $2 \AA$. These deviations could not be completely eliminated but adding a $2.1-\AA \mathrm{Rh}-\mathrm{Ti}^{n+}$ contribution improved the agreement between calculated and experimental spectra. Because of the low coordination number, there remains some uncertainty about the scatterer. It was not possible to unambiguously identify the scatterer as oxygen or titanium, although titanium as neighbor resulted in better fitting spectra. It is evident that at the low- $R$ side in the Fourier transform of the EXAFS spectrum, a small contribution is present and it is likely that this contribution is due to a $\mathrm{Rh}-\mathrm{Ti}^{\text {nt }}$ coordination.

7. Comparison with Literature Data. Recently, similar EXAFS spectra of a $\mathrm{Rh} / \mathrm{TiO}_{2}$ catalyst in the SMSI state were reported by Sakelson et al. ${ }^{36}$ They ascribed the major peak in the magnitude of the Fourier transform at the low-r side of the dominant $\mathrm{Rh}-\mathrm{Rh}$ contribution to a $\mathrm{Rh}-\mathrm{Ti}$ contribution, while our results point to a $\mathrm{Rh}^{0}-\mathrm{O}^{2-}$ contribution for the same peak in the Fourier transform. We question the assignment of this peak to $\mathrm{Rh}-\mathrm{Ti}$ for the following reasons:

(i) The above-mentioned contribution, referred to as $\mathrm{Rh}-\mathrm{X}$, resembles closely the peak in the Fourier transform of the EXAFS functions of $\mathrm{Rh} / \mathrm{Al}_{2} \mathrm{O}_{3}$ catalysts, which has unambiguously been ascribed to a $\mathrm{Rh}-\mathrm{O}$ contribution. ${ }^{28,32}$ Furthermore, we observed the same $\mathrm{Rh}-\mathrm{X}$ contribution in the "normal" as well as in the SMSI state of the catalyst. Since in the normal state there is no reason to assume $\mathrm{Rh}-\mathrm{Ti}$ coordination, the assignment of the $\mathrm{Rh}-\mathrm{X}$ peak to oxygen neighbors in the metal-support interface is much more likely.

(ii) In the fitting procedure described in ref 36 , only titanium as a neighbor was taken into account; oxygen was not tried as a possible neighbor. The fitting procedures on our spectra yield, in terms of sum-of-least-squares and variance, better results with oxygen than with titanium as scatterer in the $\mathrm{Rh}-\mathrm{X}$ contribution.

(iii) The Rh-Rh and $\mathrm{Rh}-\mathrm{Ti}$ contributions in the $\mathrm{RhTi}$ reference compound overlap both in the $k^{1}$ - and in the $k^{3}$-weighted Fourier transforms. A rough approximation indicates that the overlap is at least $25 \%$. Also, the well-known side lobe of the $\mathrm{Rh}-\mathrm{Rh}$ peak (due to the $k$-dependence in phase and backscattering functions) is hidden under the $\mathrm{Rh}$-Ti peak. In Figure 10a, the $k^{3}$-weighted Fourier transforms of the calculated $\mathrm{Rh}-\mathrm{Ti}(N=8, R=2.676)$ and $\mathrm{Rh}-\mathrm{Rh}(N=4, R=2.949)$ EXAFS spectra are shown, demonstrating their overlap. Thus, inverse transformation as performed in ref 36 , using a window to separate both contributions, definitely results in incorrect phase and backscattering functions for the $\mathrm{Rh}-\mathrm{Ti}$ absorber-scatterer pair. In Figure $10 \mathrm{~b}$ is shown the $\mathrm{Rh}-\mathrm{Ti}$ EXAFS function as we have calculated it and the same

(36) Sakelson, S.; McMillan, M.; Haller, G. L. J. Phys. Chem. 1986, 90. 1733.

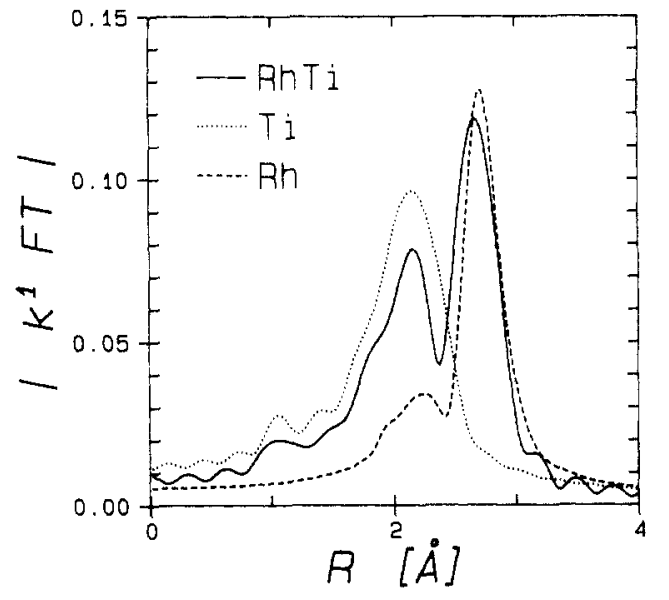

a

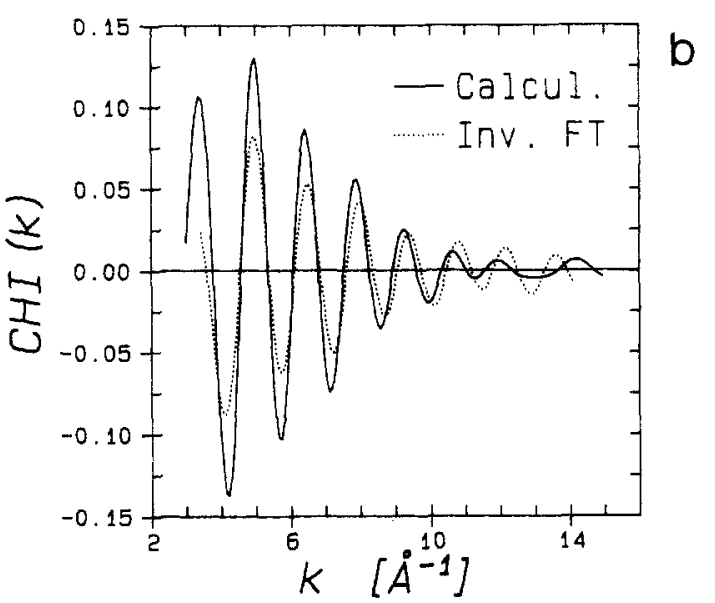

Figure 10. (a) Magnitude of the $k^{1}$-weighted Fourier transforms of (solid line) EXAFS spectrum of the RhTi alloy; (dotted line) calculated $\mathrm{Rh}-\mathrm{Ti}$ EXAFS function; (dashed line) calculated Rh-Rh EXAFS function. (b) Reference spectra of (solid line) calculated Rh-Ti EXAFS function; (dotted line) Rh-Ti EXAFS function from inverse Fourier transform.

contribution which has been achieved by an inverse Fourier transform over the window $0.00-2.38 \AA$. It is obvious that especially at lower $k$ values the differences are substantial.

(iv) Sakelson et al. stated that, after a $k^{1}$-weighted Fourier transform, the $\mathrm{Rh}-\mathrm{Rh}$ and $\mathrm{Rh}-\mathrm{X}$ contribution can be separated much better. ${ }^{36}$ However, in a $k^{1}$-weighted Fourier transform, the low- $Z$ scatterer information is much more pronounced than in a $k^{3}$-weighted Fourier transform. As a result, both $\mathrm{Rh}-\mathrm{Rh}$ and $\mathrm{Rh}-\mathrm{X}$ peaks still overlap, and the overlap is even larger. Because of the larger overlap, there is a strong destructive interference in the region between the two peaks. This can best be seen in the imaginary part of the Fourier transform. Because of the antiphase behavior of the imaginary part of the separate contributions, there is a strong destructive interference and the magnitude of the Fourier transform shows a sharp minimum between both peaks. In a $k^{1}$-weighted Fourier transform, the $\mathrm{Rh}-\mathrm{Rh}$ and $\mathrm{Rh}-\mathrm{Ti}$ contributions are therefore separated even less clearly than in a $k^{3}$-weighted Fourier transform. This can also be seen in Figure 10 , where the magnitude of the $k^{1}$-weighted Fourier transform of the RhTi alloy is compared to the separate $\mathrm{Rh}-\mathrm{Ti}$ and $\mathrm{Rh}-\mathrm{Rh}$ contributions. Because of the destructive interference, the sum of the two separate contributions (solid line) is lower in magnitude than the respective contributions at their maximum. A careful inspection also reveals that the peak maxima are shifted slightly. Also for this reason, it is incorrect to use a window in a $k^{\prime}$-weighted Fourier transform to separate the $\mathrm{Rh}-\mathrm{Rh}$ and $\mathrm{Rh}-\mathrm{X}$ contributions.

(v) It is insufficient to use a $k^{3} \chi(k)$ plot to show the result of the best fit, ${ }^{36}$ since the $k^{3}$ term strongly enhances the high- $Z$ $\mathrm{Rh}-\mathrm{Rh}$ contribution which makes the plot less sensitive to the low- $Z \mathrm{Rh}-\mathrm{X}$ contribution. A plot of $\chi(k)$ is necessary to compare experimental and calculated data. 
$\mathrm{Rh}-\mathrm{Ti}$ phase and backscattering functions have in a first approximation the same general $k$ dependence as the $\mathrm{Rh}-\mathrm{O}$ phase and backscattering functions. This is as expected, because of the low $Z$ character of both oxygen and titanium. ${ }^{37}$ As a result, it is always possible to fit a $\mathrm{Rh}-\mathrm{O}$ EXAFS function with $\mathrm{Rh}-\mathrm{Ti}$ parameters, and vice versa. A difference in backscattering amplitude can be compensated with a particular (i.e., wrong) choice of coordination number and Debye-Waller factor. Because of a different phase function, however, such a fit will result in incorrect coordination distances. Clearly, to discriminate between $\mathrm{Rh}-\mathrm{Ti}$ and $\mathrm{Rh}-\mathrm{O}$ contributions, a very careful data analysis procedure is required. The procedure which we have used in our analysis procedure is superior to the procedure described in ref 36. We believe that the assignment of the $\mathrm{Rh}-\mathrm{X}$ contribution to oxygen neighbors is correct and that the conclusion drawn by Sakelson et al. about RhTi alloy formation in the SMSI state is not justified.

\section{Final Conclusions}

From the observed neighboring $\mathrm{Ti}^{n+}$ ions, we conclude that in the SMSI state the metal particles rest on a $\mathrm{TiO}_{x}$ suboxide. This has already been suggested in the first reports on SMSI ${ }^{1,3}$ In the SMSI state, the metal particles are incapable of adsorbing $\mathrm{H}_{2}$ and as a consequence the $\mathrm{Rh}-\mathrm{Rh}$ distance has contracted by about $0.05 \AA$. The $\mathrm{Rh}^{0}-\mathrm{O}^{2-}$ distance in the metal-support interface has contracted as well, by about $0.18 \AA$. This is the result of an interaction between metal and support. In the SMSI state, the rhodium metal particles are capable of adsorbing $\mathrm{O}_{2}$ at 100 and $300 \mathrm{~K}$. Therefore, and because we found no evidence for a covering suboxide with EXAFS nor with HRTEM, we conclude that coverage is not complete or is even absent in $\mathrm{Rh} / \mathrm{TiO}_{2}$. Oxidation of the metal particles in the SMSI state, however, is suppressed, even at $300 \mathrm{~K}$. This again must be the result of an electronic metal-support interaction and cannot be explained by coverage.

Another interesting phenomenon observed has been observed with EXAFS. When the oxygen-exposed $\mathrm{Rh} / \mathrm{TiO}_{2}$ catalyst is warmed to room temperature, the $\mathrm{TiO}_{x}$ suboxide in the vicinity of the metal particles starts to reoxidize. At the same time, the metal-support interaction weakens. This proves that indeed the suboxide underneath and around the metal particles plays a key role in the anomalous properties of the supported rhodium metal particles in the SMSI state. At this point, however, it is not clear what the role of the suboxide is. A clue for further studies may possibly be found in the contribution present around $2.1 \AA$ in the EXAFS spectra of the $\mathrm{Rh} / \mathrm{TiO}_{2}$ catalyst in the SMSI state.

During the past years, the majority of the literature dealing with SMSI reported coverage. ${ }^{9-17}$ Since the results of this study do not support complete coverage, we will focus on covering in the following. Covering of metal particles by an oxide can take place in two ways. The covering oxide may have a chemical interaction or may have no interaction at all with the metal particles. When there is an interaction between covering oxide and metal particle, the oxide will "wet" the metal surface. Most authors see this kind of covering as the origin for the decrease in adsorption capacity of metal particles in the SMSI state. Such a covering would greatly enhance the number of $\mathrm{O}^{2-}$ neighbors for the metal atoms in the surface of the metal particles. Since in such a case there is an attractive interaction between oxide and metal particle (and because the state of coverage has been formed at high temperatures), the disorder in these $\mathrm{Rh}^{0}-\mathrm{O}^{2-}$ bonds that are formed in the SMSI state is expected to be small. Therefore, EXAFS should be able to detect such bonds. For instance, in the 5-atoms metal particle in Figure 9, each rhodium atom is a surface atom. In the case of complete coverage, the interfacial rhodium atoms should have seven (three more than in the normal state) $\mathrm{O}^{2-}$ neighbors and the top rhodium atom should have eight new $\mathrm{O}^{2-}$ nearest neighbors. Therefore, the $\mathrm{Rh}^{0}-\mathrm{O}^{2-}$ coordination number should increase at least by a factor of 2 or 3 . For the $\mathrm{Rh} / \mathrm{Al}_{2} \mathrm{O}_{3}$ catalyst reduced at $623 \mathrm{~K}$ and oxidized at room tem-

(37) Teo, B. K.; Lee, P. A. J. Am. Chem. Soc. 1979, 101, 2815. perature, the $R h^{0}-R h^{0}$ coordination number decreased by a factor 3 , the $\mathrm{Rh}^{0}-\mathrm{O}^{2-}$ coordination number by a factor 1.2 (cf. Table II). Relative to the $\mathrm{Rh}^{0}-\mathrm{Rh}^{0}$ coordination number, the $\mathrm{Rh}^{0}-\mathrm{O}^{2-}$ coordination number increased by a factor of 2.5. From this we concluded that the metallic kernel of the oxidized particles was covered with rhodium oxide and it proves that EXAFS can detect a covering oxide. For the $\mathrm{Rh} / \mathrm{TiO}_{2}$ catalyst in the SMSI state we certainly did not find any evidence for such as increase in $\mathrm{Rh}^{0}-\mathrm{O}^{2-}$ coordination number. In this study, after reduction at $723 \mathrm{~K}$, the $\mathrm{Rh}^{0}-\mathrm{O}^{2-}$ coordination number increased from $1.3 \pm$ 0.3 to $1.9 \pm 0.3$. In our previous study, we found a small decrease in the $\mathrm{Rh}^{0}-\mathrm{O}^{2-}$ coordination number. The analysis of the EXAFS spectrum of the $\mathrm{Rh} / \mathrm{TiO}_{2}$ catalyst reduced at $473 \mathrm{~K}$ was hampered by the presence of $\mathrm{Rh}_{2} \mathrm{O}_{3}$. Therefore, the $\mathrm{Rh}^{0}-\mathrm{O}^{2-}$ coordination number for this catalyst is rather inaccurate (after correction, this coordination number is 1.3) and, in our view, too low. Therefore, the apparent increase in the $\mathrm{Rh}^{0}-\mathrm{O}^{2-}$ coordination number when the reduction temperature is increased is insignificant and certainly too small to justify the conclusion that the metal particles are tightly covered with $\mathrm{TiO}_{x}$. On the basis of these $\mathrm{Rh}^{0}-\mathrm{O}^{2-}$ coordination numbers, one could state that perhaps a small (partial) covering of the rhodium metal particles has taken place. It is also possible that a very loose covering occurs; this induces only a small number of additional $\mathrm{O}^{2-}$ neighbors. In the following paragraph we will discuss the effects of such a loose covering.

When there is no interaction between metal and support, wetting and tight packing of the oxide around the metal particles will not take place. Coverage then simply means the physical presence of oxide crystallites over the metal particles. The spread in the $\mathrm{Rh}^{0}-\mathrm{O}^{2-}$ distances will then be large, which makes it impossible for EXAFS to detect the oxide. ${ }^{38}$ On the basis of the EXAFS results, we therefore cannot exclude the presence of a loosely bound $\mathrm{TiO}_{x}$ suboxide on top of the metal particles. Such a coverage does not have to be complete, but may still be able to suppress adsorption of hydrogen and carbon monoxide.

From the oxygen adsorption experiments we learned that metal atoms are exposed. Our results therefore exclude complete coverage for rhodium metal particles supported on $\mathrm{TiO}_{2}$ in the SMSI state. The metal particles may, however, be partially covered with $\mathrm{TiO}_{x}$ if this covering oxide does not tightly adhere to the metal surface. But such a loosely packed covering oxide, which does not interact with the metal particles, cannot be responsible for the observed behavior of the SMSI-state catalyst during oxygen exposure.

We feel that a loose coverage may occur in the SMSI state and may also explain the difference in catalyst performance between metals supported on the traditional supports like $\mathrm{Al}_{2} \mathrm{O}_{3}$ and on reducible supports (see, for example, ref 39 ). It is our conviction, however, that coverage alone cannot explain the large decrease in adsorption capacity (usually one order of magnitude) of the rhodium metal particles in the SMSI state in the discussed $\mathrm{Rh} / \mathrm{TiO}_{2}$ catalyst. From this and many other studies in this field ${ }^{7,10-13,16-20}$ it is clear that SMSI is a complex phenomenon and may vary from system to system. It may well prove impossible to condense this complexity into one model which can explain all the results presented up to now in the literature on SMSI. Rather, the explanation for SMSI may vary from system to system. The present study indicates that coverage is a phenomenon unlikely to occur in $\mathrm{Rh} / \mathrm{TiO}_{2}$. Although, based on the EXAFS results, coverage cannot completely be excluded, it is evident that if a covering oxide is present, the interaction between this covering oxide and the surface metal atoms is weak. But such a loose packed weakly interacting oxide cannot account for the fact that oxidation was greatly suppressed when the surface metal atoms were exposed to oxygen. Therefore, an electronic perturbation is the most likely explanation for the anomalous properties of these small rhodium metal particles supported on $\mathrm{TiO}_{2}$ in the SMSI state.

(38) Eisenberger, P. Brown, G. S. Solid State Commun. 1979, 29, 481

(39) Levin, M. E.; Salmeron, M.; Bell, A. T.; Somorjai, G. A. Faraday Symp. Chem. Soc. 1986, 21, paper 10. 
Acknowledgment. This study was supported by the Netherlands Foundation for Chemical Research (SON) with generous financial aid from the Netherlands Organisation for the Advancement of Pure Research (ZWO). With pleasure, the authors acknowledge the skilful and invaluable assistance of the Daresbury SRS staff. And, last but not least, without the help of several colleagues from the Eindhoven University (F. W. H. Kampers, F. B. M. van Zon, and J. van Grondelle) and the Leiden State University (F. C. Mijlhoff, M. J. P. Botman and H. den Hartog), these experiments would not have been performed.

Registry No. Rh, 7440-16-6; $\mathrm{TiO}_{2}, 13463-67-7 ; \mathrm{O}_{2}, 7782-44-7$.

\title{
Electron Bombardment Fragmentation and Intramolecular Ion-Molecule Reactions of Size-Selected $\mathrm{C}_{2} \mathrm{H}_{4}$ Clusters
}

\author{
U. Buck, ${ }^{*}$ Ch. Lauenstein, H. Meyer, and R. Sroka \\ Max-Planck-Institut für Strömungsforschung, Bunsenstrasse 10, D 3400 Göttingen, \\ Federal Republic of Germany (Received: July 9, 1987)
}

\begin{abstract}
Ethylene clusters that are generated in an adiabatic expansion with $\mathrm{He}$ are size selected by scattering from a He beam. By measurement of angular-dependent mass spectra and time-of-flight distributions at one monomer fragment mass $(m=26$ $\mathrm{amu}$ ), the complete fragmentation pattern for electron impact ionization of clusters up to tetramers is obtained for electron energies of $100 \mathrm{eV}$. For ionization of the dimer aside from typical monomer fragment masses $(25-28 \mathrm{amu})$ the results are dominated by ion-molecule reactions within the cluster leading to the dimer to fragment channels at $m=29,41$, and 55 amu. No product is observed at the parent mass $56 \mathrm{amu}$. For larger clusters the main fragmentation product is the $\mathrm{C}_{4} \mathrm{H}_{8}{ }^{+}$ (56) ion which is stabilized by third-body collisions with the other partner molecules within the cluster. The scattering analysis is also used for deriving information on the cluster formation and density as a function of the concentration and stagnation pressure as well as on the energy transfer to the clusters during the collisions with $\mathrm{He}$.
\end{abstract}

\section{Introduction}

Interest in the properties and dynamics of atomic and molecular clusters has dramatically increased during recent years. ${ }^{1}$ Part of this interest comes from the fact that clusters provide a bridge between molecular physics and the condensed phase. Experimental studies of neutral clusters frequently involve ionization, followed by analysis and detection of cluster ions in a mass spectrometer. ${ }^{2}$ Numerous experimental results have been published in which the measured ion distributions are attributed to properties of the neutral precursors. However, this is a very dangerous procedure, since significant fragmentation following the ionization process has been observed in many experiments. ${ }^{3-10}$

It is very difficult to get quantitative information about this fragmentation process, since, at present, there is no cluster source available that produces only one cluster size. Therefore the cluster size has to be labeled by an experimental method independent from the ionization process. This can either be done by spectroscopic methods ${ }^{11-14}$ or by a scattering process. ${ }^{15,16}$ In the latter

(1) See, for example the volumes of the journals: Ber. Bunsen-Ges. Phys Chem. 1984, 88. Surf. Sci. 1985, 156. Z. Phys. D: At. Mol. Clusters 1986, 3 .

(2) Märk, T.; Castleman, A. W., Jr. Adv. At. Mol. Phys, 1985, 20, 65.

(3) Dehmer, P. M.; Pratt, S. T. J. Chem. Phys. 1982, 76, 843.

(4) Worsnop, D. R.; Buelow, S. J.; Herschbach, D. R. J. Phys. Chem $1984,88,4506$.

(5) Birkhofer, H. P.; Haberland, H.; Winterer, M.; Worsnop, D. R. Ber Bunsen-Ges. Phys. Chem. 1984, 88, 207. 195 .

(6) Stephan, K.; Märk, T. D. Int. J. Mass Spectrom. Ion Phys. 1983, 47,

(7) Echt, O.; Kreisle, D.; Knapp, M.; Recknagel, E. Chem. Phys. Lett 1984, 108,401

(8) Echt, O.; Dao, P. D.; Morgan, S.; Castleman, A. W., Jr. J. Chem. Phys $1985,82,4076$

(9) Kamke, W.; Kamke, B.; Kiefl, H. U.; Hertel, I. V. J. Chem. Phys 1986, 84, 1325 .

(10) Recknagel, E. Ber. Bunsen-Ges. Phys. Chem. 1984, 88, 201 method the different kinematical behavior of the clusters in a scattering experiment is used to separate them from each other. By measuring the angular and velocity distribution of the scattered clusters, their intensity can be uniquely attributed to a certain cluster size independent from the subsequent detection process. In particular, this procedure allows the determination of the fragmentation during the ionization process if the intensity of certain clusters is detected at different masses. Applications to the fragmentation by electron impact ionization of the van der Waals clusters $\mathrm{Ar}_{n}{ }^{16}$ and $\left(\mathrm{CO}_{2}\right)_{n}{ }^{17}$ and the stronger bonded $\left(\mathrm{NH}_{3}\right)_{n}{ }^{18}$ clusters have been carried out. In the present contribution we present a detailed investigation of the fragmentation of ethylene clusters $\left(\mathrm{C}_{2} \mathrm{H}_{4}\right)_{n}$. This is an especially complicated case, since already the monomer is fragmented upon ionization by electron bombardment. There has been great interest in these clusters in photoionization ${ }^{19}$ and infrared photodissociation ${ }^{20,21}$ processes. Some of the measurements indicate that the mass

(11) Geraedts, J.; Stolte, S.; Reuss, J. Z. Phys, A 1982, 304, 167

(12) Hopkins, J. B.; Powers, D. E.; Smalley, R. E. J. Chem. Phys. 1981, 85,3739 .

(13) Gough, T. E.; Miller, R. E. Chem. Phys. Lett. 1982, 87, 280

(14) Bombach, R.; Honegger, E.; Leutwyler, S. Chem. Phys. Lett. 1985 118,449

(15) Buck, U.; Meyer, H. Phys. Rev. Lett. 1984, 52, 109

(16) Buck, U.; Meyer, H. J. Chem. Phys. 1986, 84, 4854

(17) Buck, U.; Lauenstein, Ch.; Sroka, R.; Tolle, M. Z. Phys. D.: At. Mol. Clusters, to be published.

(18) Lauenstein, Ch. Diplomarbeit, Universität Göttingen, 1986. Buck U.; Meyer, H.; Nelson, Jr., D.; Fraser, G.; Klemperer, W. J. Chem. Phys, in press.

(19) Ceyer, S. T.; Tiedemann, P. W.; Ng, C. Y.; Mahan, B. H.; Lee, Y. T. J. Chem. Phys. 1979, 70, 2138.

(20) Cassasa, M. P.; Bomse, D. S.; Janda, K. C. J. Chem. Phys. 1981, 74,

(21) Hoffbauer, M. A.; Liu, K.; Giese, C. F.; Gentry, W. R. J. Chem. Phys. 1983, 78, 5567 